\title{
محددات صراع العمل والاسرة لدى المرأة الريفية العاملة المتزوجة بمحافظة الغربية
}

\author{
محمد فتح الله أبو اليزيد عباد الله
}

قسم الأقتصاد الزراعى - كلية الزراعة - جامعة طنطا لهاعل

mohammed.ebadallah@agr.tanta.edu.eg

Received: Dec. 4, 2016

Accepted: Dec. 13, 2016

الملخص

يهذف البحث الحالى الى تقييم البنية العاملية لدقياس صراع العقل والاسرة، والتعرف على محددات صراع العمل والاسرة. ولتحقيق أهداف البحث، تم اختيار عبنة عنقودية عددية مكونة من 203 من الدبحوثات الريفيات العاملات والدتزوجات،

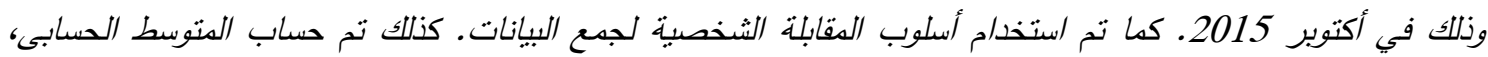
والانحراف الدعيارى، والنسب الدئوية، والانحدار الخطى الهتعدد الهريى لحساب النتائج. واظهرت أهم نتائج التحليل متعدد

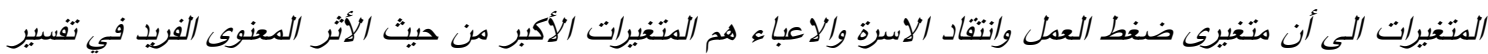

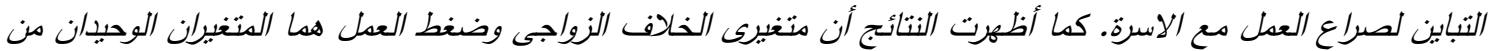

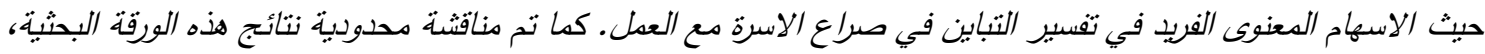
وكزلك المجالات البحثبة المستقبلية. الكلمات المفتاحية: تحليل عاملى توكيدى، صراع العمل والاسرة، المرأة الريفية العاملة المتزوجة، محافظة الغربية، الانحدار الخطى المتعدد الهريى.

المكانة الاجتماعية لدى المرأة العاملة والمتزوجة. فبعد أن

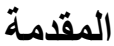
كانت مهنة المرأة قاصرة على أداء الأدوار المنزلية ورعاية الأبناء، أصبحت المرأة العاملة تقوم بأدوار متعددة داخل

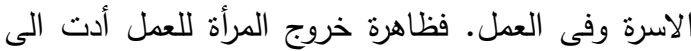
احداث هزة عنيفة غيرت في المواضع الاجماعية للمرأة

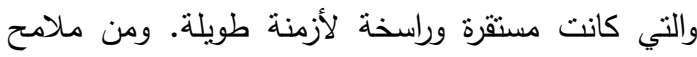

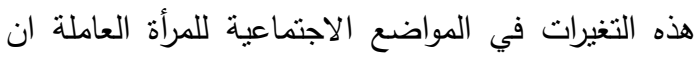

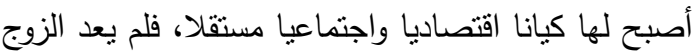
هو الملاذ الوحيد لها في الحياة الاجتماعية، فقد أوجد العمل لها ملاذا اخر ينافس مكانة الزوج بل ويتغلب عليها أحيانا. وملمح أخر من هذه التغيرات وهو عدم قدرة المرأة

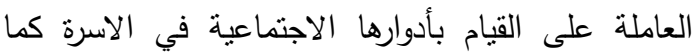
ينبغي. وقد أدى ذلك الى تعرض بعض النساء العاملات الى ارهاق شديد ونزاع أدوار وضغوط. وتطلب الامر

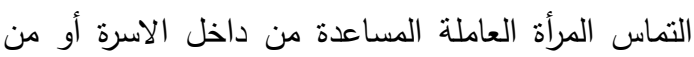

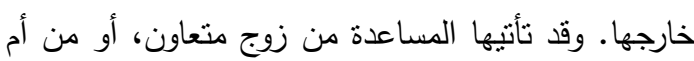

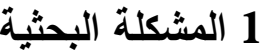
أصبحت قضية العمل والاسرة من أهم القضايا في المجتمعات المعاصرة. فزيادة مشاركة المرأة في قوة العمل العل منذ السبعينيات من القرن العشرين، أدى الى أحداث تغيرات اجتماعية جعلت من موضوع العمل والاسرة من الموضوعات الهامة للبحث والدراسة من قبل الباحثين وصناع القرار، وذلك رغبة منهم فى فهم إدراك الناس لصراع العمل والاسرة، وكنلك فهم ملامح هذا التغير الاجتماعى في المواضع الاجتماعية وبخاصة لدى المرأة العاملة المنتوجة، والصعوبات التي نواجهها لتحقيق النوازن

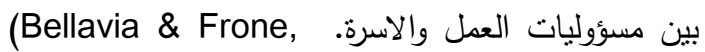
2005; Hill, 2005; Winslow, 2005) وفى هذا السياق فقد عدد عبداللا واخرون، (2014،

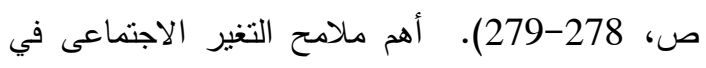




\section{Ebad-Allah}

(كمورد الوقت ومورد الطاقة) وذلك من أجل تلبية احتباجات هؤلاء الافراد. ولان حجم هذه الموارد ثنابت، لكرد فالمشاركة في أدوار متعددة قد ينتج عنه تخصيص الآلمران موارد

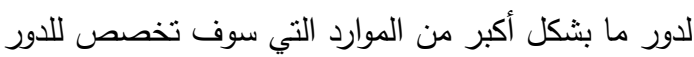
الاخر • Rothbard, 2001)

كما يثير مفهوم صراع العمل والاسرة الى التقييم

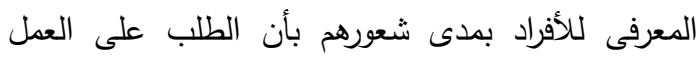

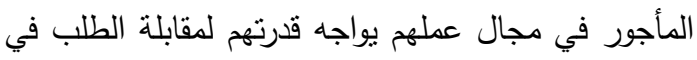

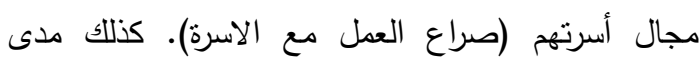

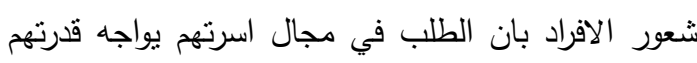
على تلبية احتياجات عملهم (صراع الاسرة مع العمل).

(Voydanoff, 2005a)

في السابق كان مفهوم صراع العمل والاسرة يستخدم

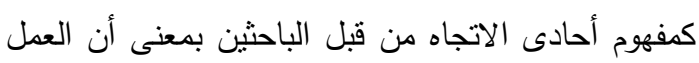

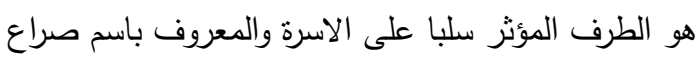
(Carlson, Kacmar and William, العمل الاسرة

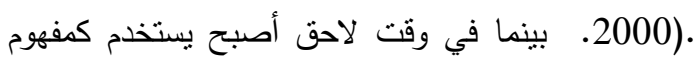

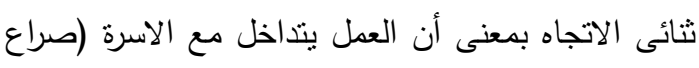

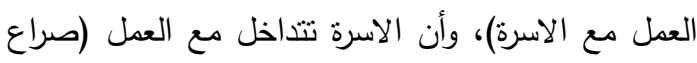

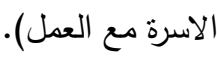

كما صنف كل من Beutell Greenhaus،

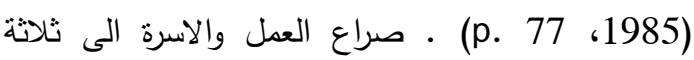
أنشكال وهى: صراع قائم على الوقت

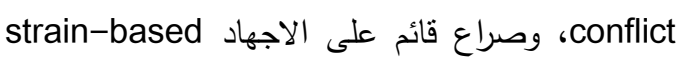
behavior-conflict based conflict تكريس وقت لدور ما يجعل من الصعب ثلبية منطلبات

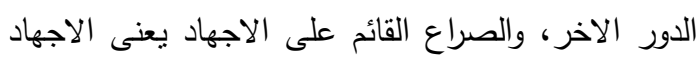

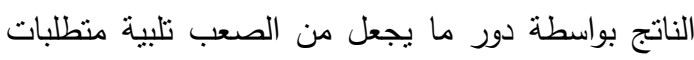

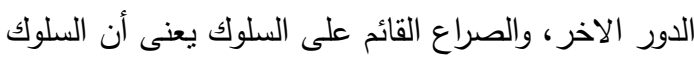
المطلوب في دور ما يجعل من الصعب تلبية منطلبات

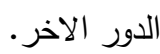

في حين صنف كل من Boles Netemyer و الاخر، (p.401, 1996) McMurrian
حانية أو من خادمة مأجورة. كما قد نستعين بدار حضانة لرعاية الأبناء. وتلك كلها مظاهر تغير في الاسرة العربية. كذلك من مظاهر التغير الاجتماعى في مكانة المرأة العاملة هي الاعتماد على التكنولوجيا الحديثة في أداء

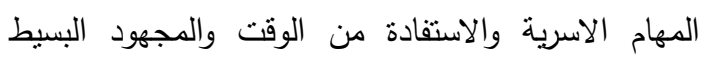

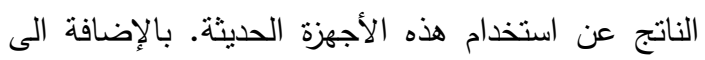

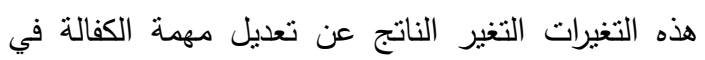

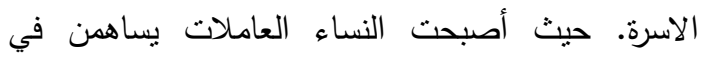
ميزانية الاسرة ببعض أو كل ما يحصلن عليه من دخل.

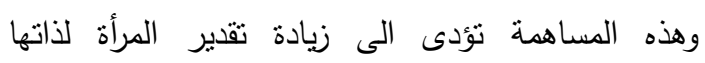

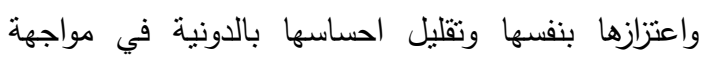

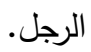
ولان ظاهرة عمل المرأة وما نتج عنها من القيام بأدوار متعددة قد يترتب عليها صراع بين مجال العمل ومجال

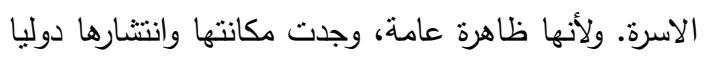

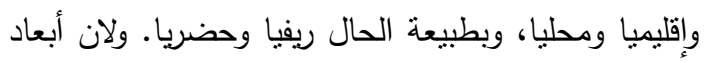
هذا الصراع ومحدداته لم يتم دراستها من قبل بالقدر

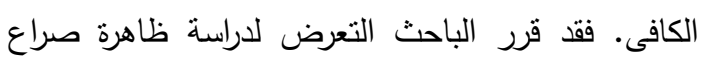
العمل والاسرة لدى المرأة الريفية المتزوجة العاملة، لمزيد

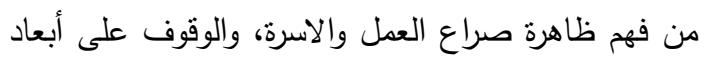

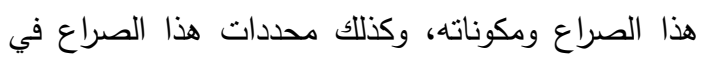
البيئة الاجتماعية الريفية المصرية وتحديدا لدى المرأة

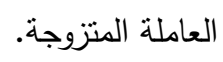

\section{2. الاستعراض المرجعى}

1.2 مفهوم صراع العمل ولاستة Work- Family

\section{Conflict Concept}

أثنار كلا من Beutell Greenhaus ، 1985) ، p. 77 . أن صراع العمل والاسرة هو شكل من أشكال

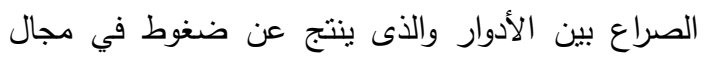

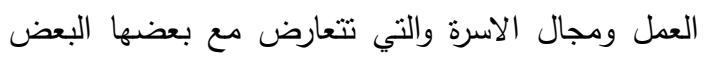
في علاقة ما. بمعنى أن المشاركة في دور العمل (الاسرة) يؤثر بشكل صعب على المشاركة في دور الاسرة (العمل). فالأفراد يثغلون أدوارا متعددة، والتي يتم نرتيبها كموارد 
التهيدات من المكن أن تهدد المواضع الاجتماعية

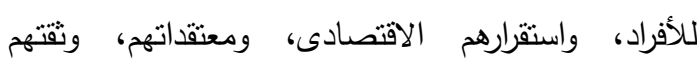
بأنفسهم، كل هذه الخسائر فى الموارد تعد مهمة لهؤلاء

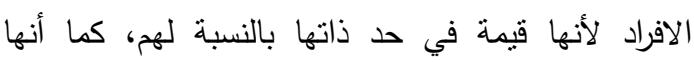

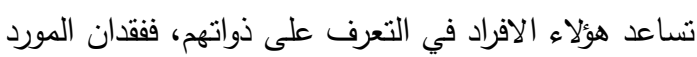

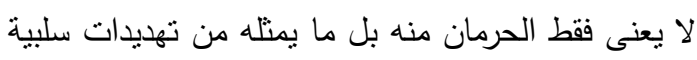

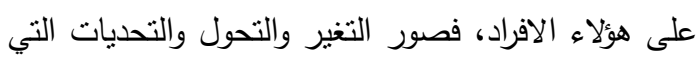
يتعرض لها هؤلاء الافراد قد تمثل لهم تهديدات في حالة ما لها

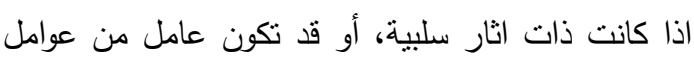
حفظ الموارد في حالة ما اذا كانت ذات اثار إيجايية، وذلك بالتقليل من حدة هذه الضغوط.

ومن منطلق منظور حفظ الموارد تحجج Voydanoff بينهما قدر من المواءمة، فالمطالب (كالوقت، والاجهاد، فئان والتوقعات)، يقصد بها المناخ البنائى أو النفسى والمرتبط لئل

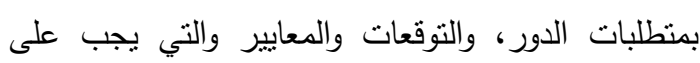
الفرد الاستجابة لها أو تنبيها بواسطة بذل الجهات الفئر الفيزيقى

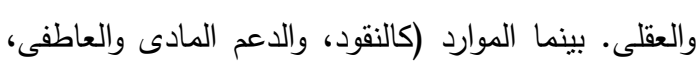

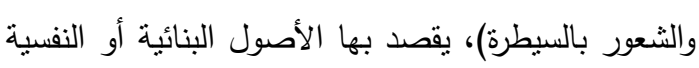

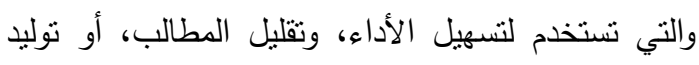
موارد جديدة. درجة هذه المواءمة بين المطالب والموارد

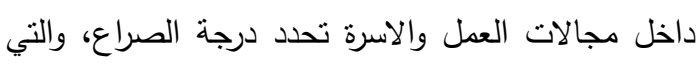

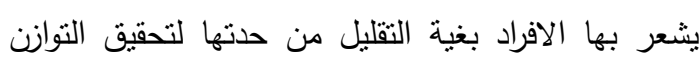
بين حياة العمل وحياة الاسرة. بمعنى اخر فان تجاوز

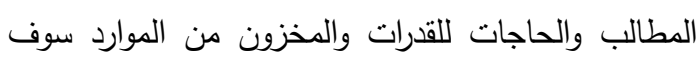
يؤدى الى حدوث الصراع. كذللك وصف كل من ون الب الكورد Boles, Mcmurrian, Netemyer الصراع بين العمل والاسرة يشبه التتافر والذى يظهر عندما يكون الوقت المخصص لقضاء متطلبات مسؤوليات مهنية معينة يتداخل مع أو يحد من كمية الوقت المتاح لأداء

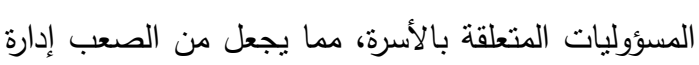
كليهما.

فخصائص العمل من الممكن أن ترتبط بشكل مباشر

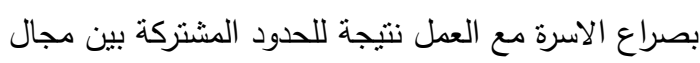

الى بعدين. اثشتمل البعد الأول على بعد الوقت والبعد

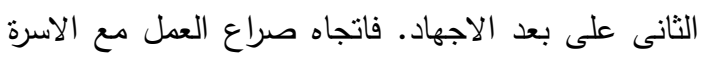

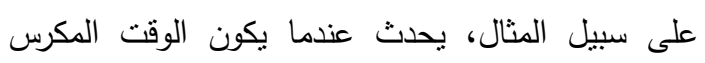

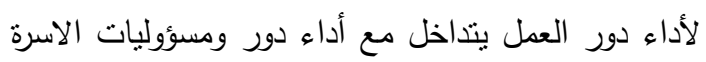

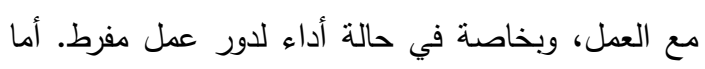

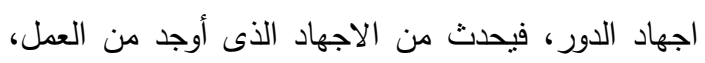

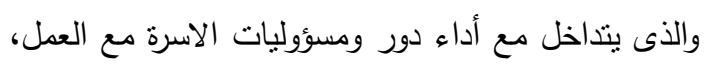

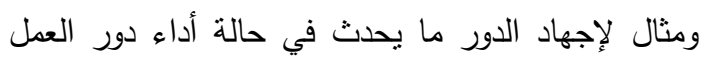
والذى يسبب تهيج وقلق فيترتب عليه اجهاد يؤثر على أداء

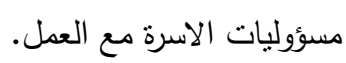
والباحث في هذا البحث يتبنى مفهوم صراع العمل والاسرة كمفهوم ذو اتجاهين، الاتجاه الأول يعبر عن تأثثر لئن

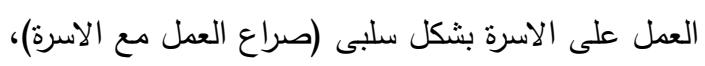

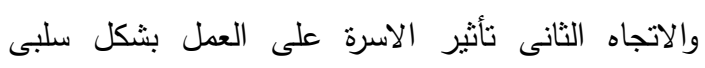

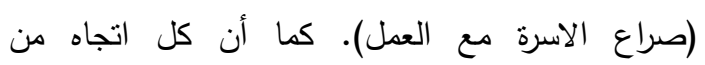

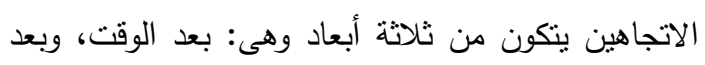

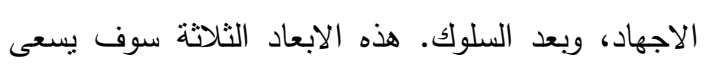

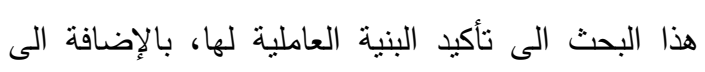

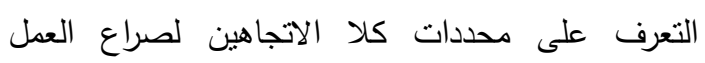
والاسرة.

\section{2 نظرية حفظ المولري وصراع العمل ولاستة} مفهوم حفظ الموارد Conservation of resources

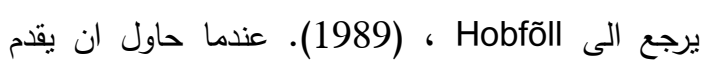
نموذجا جديدا لفهم ظاهرة الضغط النفسى. وينطلق

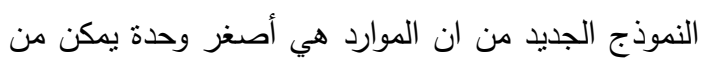

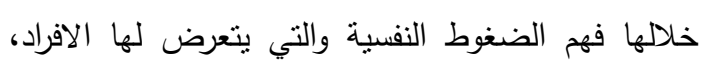

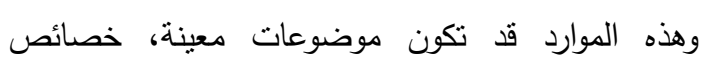

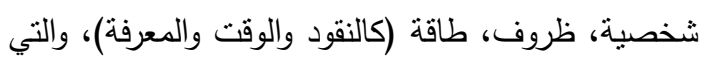
تعد أداة ذات قيمة لتحقيق أهداف معينة. ومن أمثلة هذه ولهن

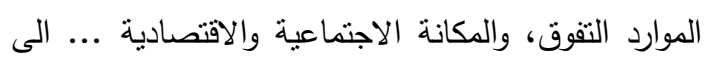
غير ذلك.

والظروف البيئية المحيطة قد تمثل تهديدا للأفراد الفاعلين، والتي قد تؤدى الى استنزاف هذه الموارد، وهذه تهذي 
الأدوار كأدوار العمل، سوف يحد من الموارد لنوع الأدوار

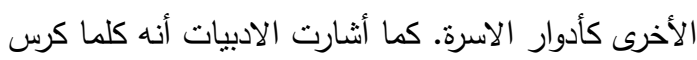

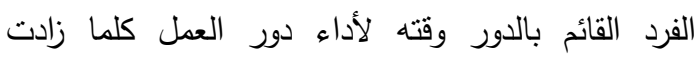
احتمالية جلب مشاكل العمل معه الى المنزل. وكلما زاد

صراع العمل والاسرة. (Hall and Richter, 1988) كذللك مع وجود بيئة عمل من علاقات الصداقة بين العاملين وأسرهم، سوف تساعد هذه البيئة على تقليل

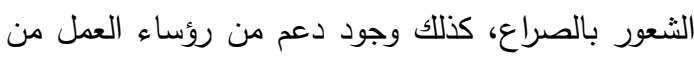

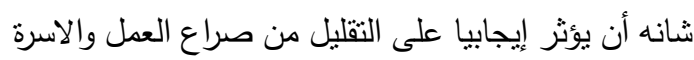
(Clark, 2002 ; Grzywacz \& Marks, 2000 ; Mennino et al., 2005 ; Nomaguchi, 2012; في حين توصلت ادبيات أخرى : Voydanoff, 2005b) الى وجود علاقة ارتباطية سالبة بين دعم المشرف في تئ العمل وصراع العمل والاسرة وصراع الاسرة والعمل. (Blanch and Aluja, 2012)

أما عن الدخل الثهرى الاسرى فان ارتفاع الدخل

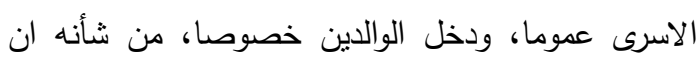

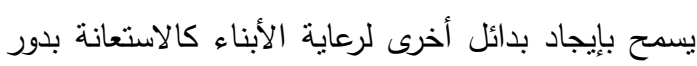

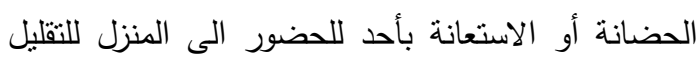

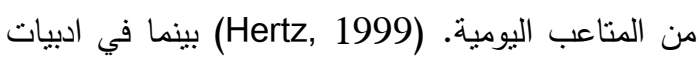

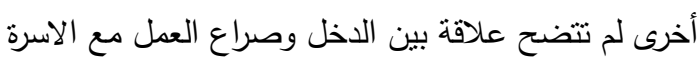
أو صراع الاسرة مع العمل. - Beutell and Wittig) berman, 1999; Frone and Russell, 1997;

Henderson, 2014)

هذا وقد توصل البعض الاخر الى وجود علاقة ارتباطية موجبة بين الدخل وصراع العمل والاسرة.

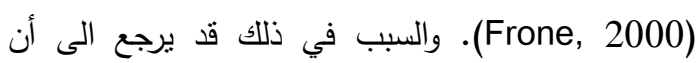

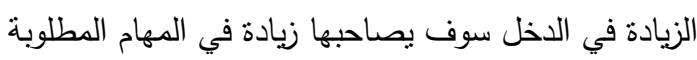
في العمل مع وقت أكثر. فيما نوصلت بعض الأن النتائج الاخرى الى عكس ذلك، حيث وجد أن الافراد ذوى الدخول

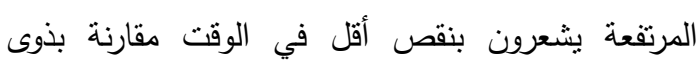
الدخول المنخفضة. (لفئة (Voydanoff and Kelly, 1984) وعلى مستوى متغيرات نسق الاسرة كمتغير عدد الأبناء أقل من 4 سنوات، ومتغير الخلاف الزواجى، ومتغير الاتيرة
العمل ومجال الاسرة، من خلال طبيعة المطالب والموارد بين مجالات العمل والاسرة. (Voydanoff, 2005b) وانعكاسا لندرة الموارد لأداء أكثر من دور في وقت واحد، فان تجارب الصراع بين العمل والاسرة تجعل حدوث هaratepe and Bekteshi, ها الصراع أمرا حتميا. (2008 فالطلب العام على دور ما سواء هذا الطلب

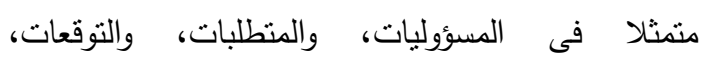
والواجبات، والالتزامات، وغيرها من مترادفات والتي تعبر

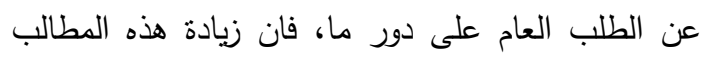

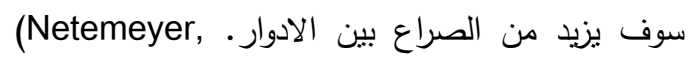
Boles, and McMurrian, 1996, p.401) يشعرن بفرض مزيد من المسؤوليات الاسرية عليهن أكثر

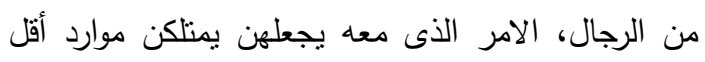

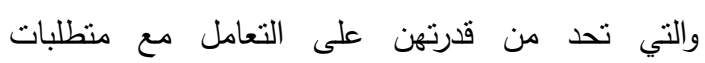
العمل.(Hobföll, 1989)

\section{2}

تناولت الادبيات العديد من المتغيرات للتعرف على علاقتها ودرجة تأثثرها على ظاهرة صراع العمل والاسرة. وبصفة عامة تصنف هذه المتغيرات الى ثلاث مجموعات متمايزة وهى متغيرات متعلقة بنسق العمل، ومتغيرات

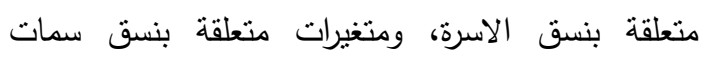

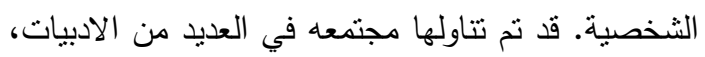
بينما نم تناول بعضها في ادبيات أخرى.

فعلى مستوى متغيرات نسق العمل كمتغير ضغط

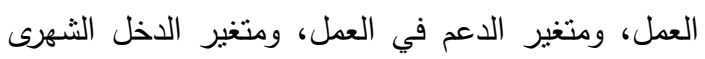

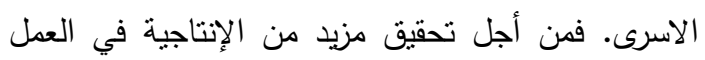
يتعرض الفرد للعديد من الضغوط في العمل والتي تثعره بصعوبة مقابل منطلبات العمل بسبب مسؤوليات الاسرة. (Grzywacz \& Marks, 2000; Nomaguchi, 2012; Voydanoff, 2005b)

وطبقا لنظرية حفظ الموارد ل Hoboföll، (1989).

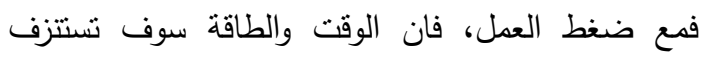
بحيث ان الطلب المرتفع والنوقعات المرتفعة لنوع ما من الطنة 
الامتداد السلبى للأسرة على العمل (صراع الاسرة مع (العمل). (Crzywacz and Marks, 2000) وعن انتقاد الاسرة والاعباء فان كثرة الانتقاد الموجه للام وبخاصة من الأبناء نتيجة لعدم مشاركتها في

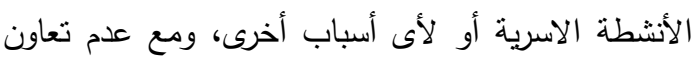

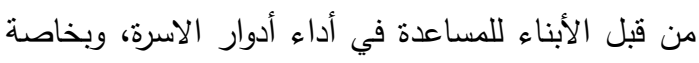

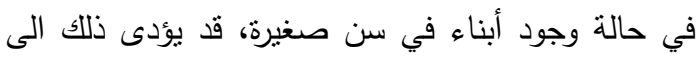
زيادة حدة الصراع بين العمل والاسرة. هذا وقد توصلت الادبيات الى وجود تأثير معنوى سالب عند المستوى ليادي

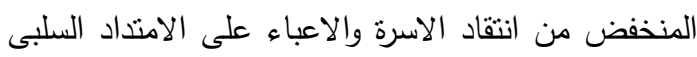

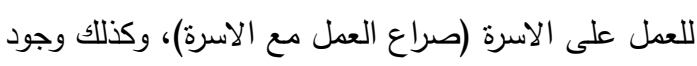

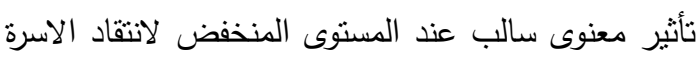

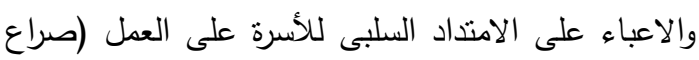
الاسرة مع العمل). (Grzywacz and Marks, 2000) أما على مستوى بعض متغيرات سمات الثخصية، فقد

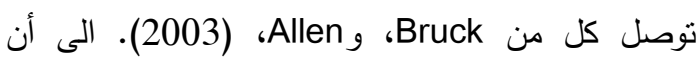

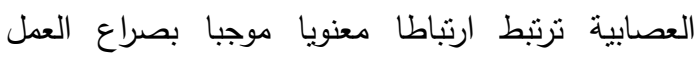

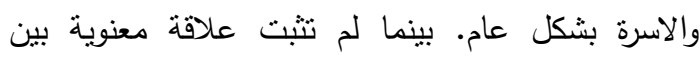

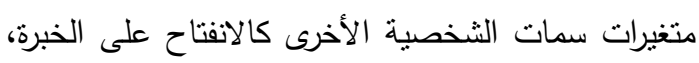
وحيوية الضمير، والمقبولية وصراع العمل والاسرة بشكل

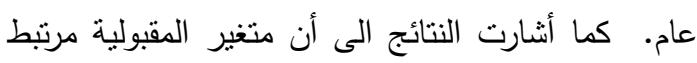

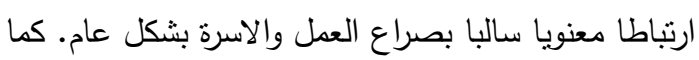
أنشارت نتائج أخرى الى أن متغير الانفتاح على الخبرة

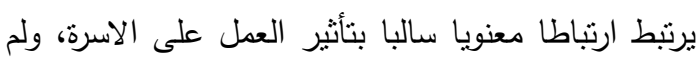
تثبت علاقة معنوية بين متغير الانفتاح على الخبرة وتأثير الاسرة على العمل. Wayne, Musisca, and في حين أثنارت بعض النتائج الى Fleeson, 2004) وجود تأثير معنوى موجب لاى كل من المرأة والرجل

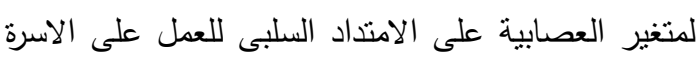

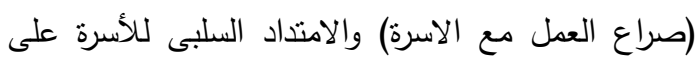

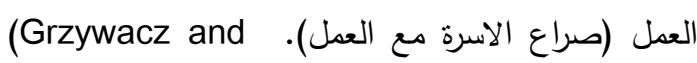
Marks, 2000)
انتقاد الاسرة والاعباء. فقد أنشارت الادبيات الى أن المرأة

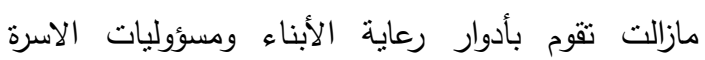

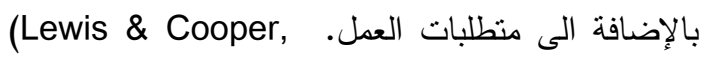
1977, 1988; Parasurman \& Greenhaus, (1997 كما توصلت النتائج الى أن وجود أطفال في سن

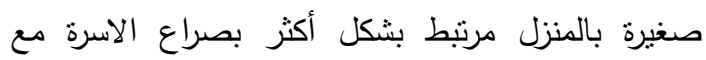
العمل. (Dilworth, 2004; Mennino et al., 2005) من منطلق أن ذلك سوف يحتاج الى طلب أكبر على

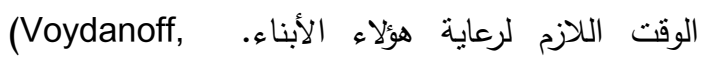

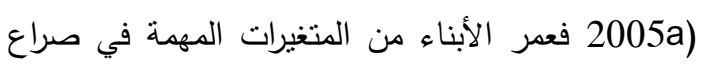

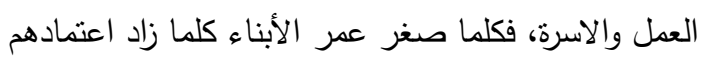
على الاباء، ومن هذا المنطلق فالأسرة التي تحتوى على الأنى

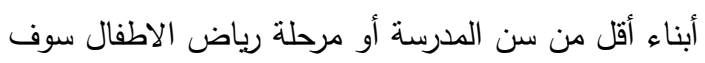

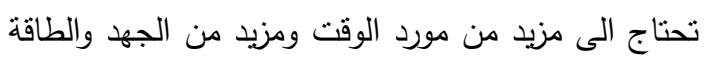

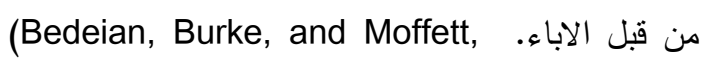
(1988 فعر الأبناء من المتغيرات ذات الأثر المعنوى

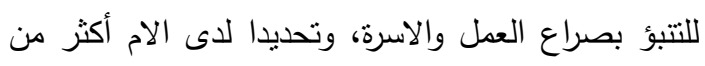

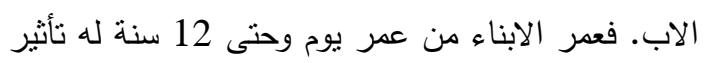

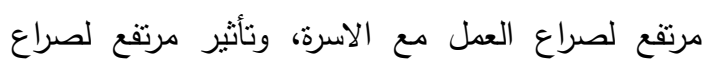

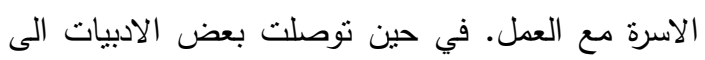

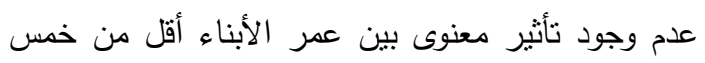

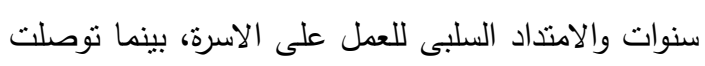
نفس الدراسة الى نأثير معنوى ايجابى بين عمر الأبناء أقل لأل

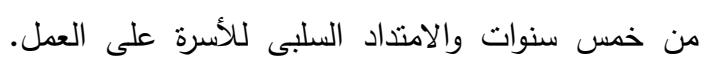
(Grzywacz and Marks, 2000) أما عن الخلاف الزواجى، فعدم تفهم الزوج لطبيعة

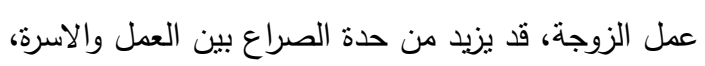
وبخاصة اذا لم يتوفر قدر من التعاون بين الزوجين،

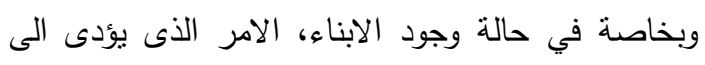

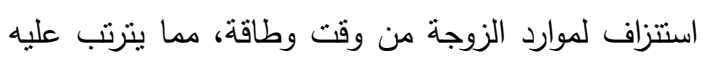
زيادة حدة الصراع بين العمل والاسرة. هذا وقد أثنارت

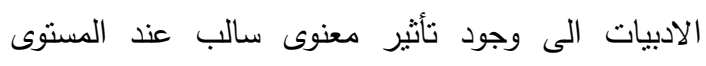

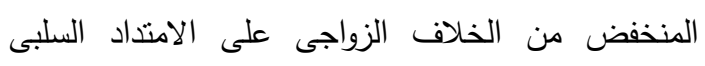

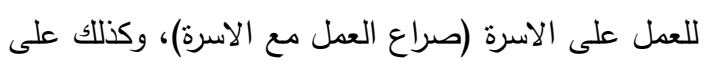


الثخصية كمتغيرات (مستقلة) من جهة، ومتغير صراع

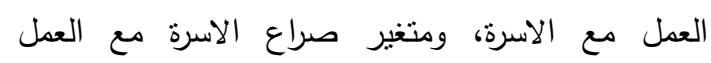
كتنغيرات (تابعة) من جهة أخرى. ولاختبار صحة هذه العلاقات الارتباطية المتعددة، تم صياغة الفروض البحثية النالية:

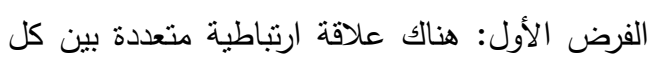

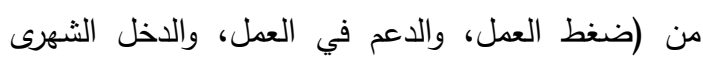
الاسرى) مجتمعه وصراع العمل مع الاسرة.

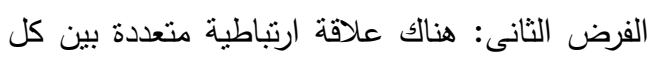

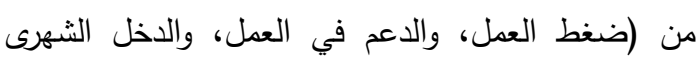

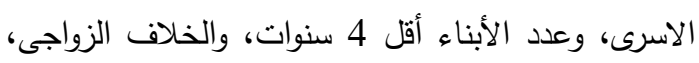
وانتقاد الاسرة والاعباء) مجتمعه وصراع العمل مع الاسرة. الفرض الثالث: هناك علاقة ارتباطية متعددة بين كل

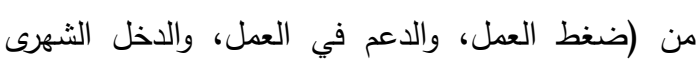

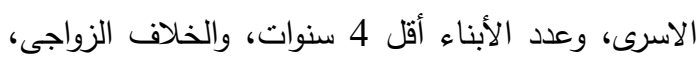

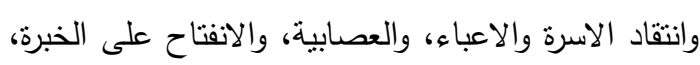

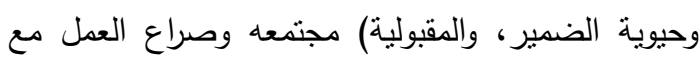

الفرض الرابع: هناك علاقة ارتباطية متعددة بين كل

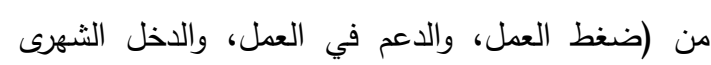
الاسرى) مجتمعه وصراع الاسرة مع العمل.

الفرض الخامس: هناك علاقة ارتباطية متعددة بين كل

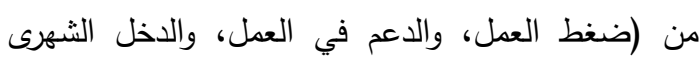

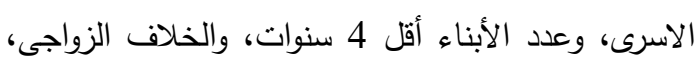
وانتقاد الاسرة والاعباء) مجتمعه وصراع الاسرة مع العمل. الفرض السادس: هناك علاقة ارتباطية متعددة بين كل

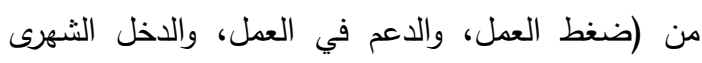

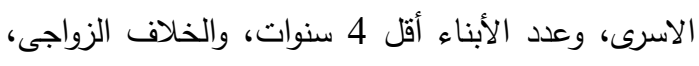

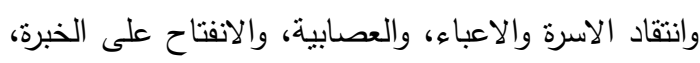

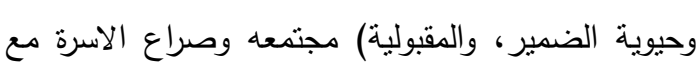

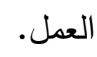

ولاختبار صحة هذه الفروض البحثية نم وضعها في

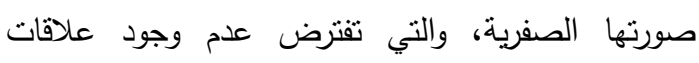
ارتباطية متعددة.

\section{3. أهمية البحث}

ترجع أهمية هذا البحث الى تعريب واستخدام مقياس

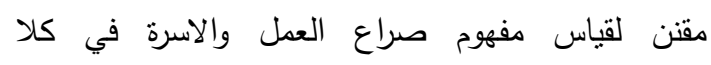
الاتجاهين، اتجاه صراع العمل مع الاسرة، واتجاه صراع الاسرة مع العمل، وتطبيقه في ظروف البيئة الاجتماعية الجاه الجاه

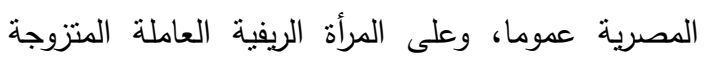

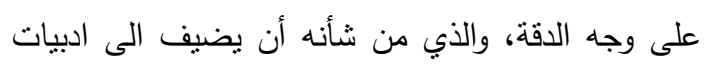
ظاهرة العمل والاسرة لدى المرأة المصرية الريفية العاملة.

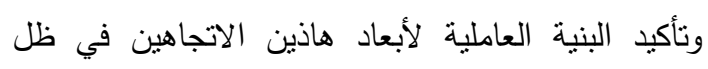
الظروف المصرية. كذلك تقديم مزيد من الفهم لظاهرة

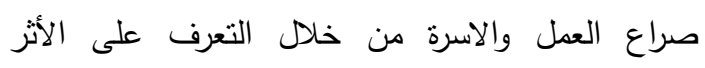
المعنوى الفريد لبعض متغيرات نسق العمل، ونسق الاسرة،

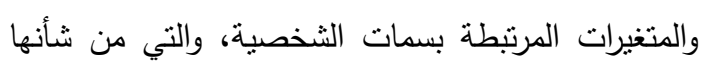

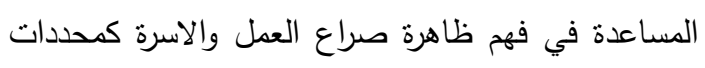

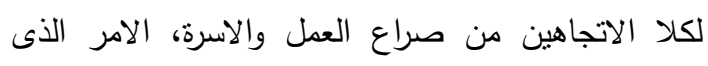

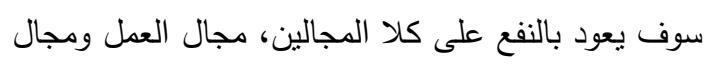

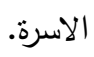

\section{4. - أهداف البحث} - تأكيد البنية العاملية لمكونات مقياس صراع العمل مع العاف الاسرة. - تأكيد البنية العاملية لمكونات مقياس صراع الاسرة مع العمل. - تقييم نموذج صراع العمل مع الاسرة.

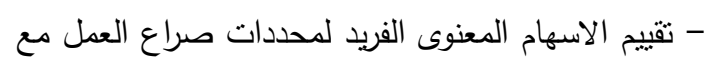
الاسرة. - تقييم نموذج صراع الاسرة مع العمل. - تقييم الاسهام المعنوى الفريد لمحددات صراع الاسرة مع الاعرة العط العمل. - العن وبناءا على ما تقدم من أدبيات سواء على مسنوى العلى

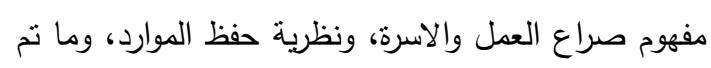

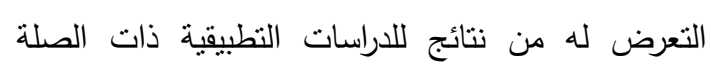

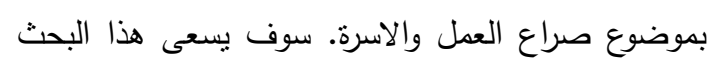

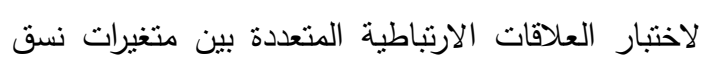

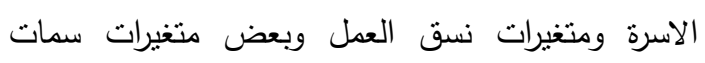


انتصت أغلب المبحوثات الى فئة التعليم الجامعى وما بعد

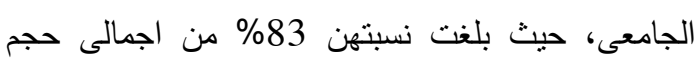
العينة. وعند تصنيف المبحوثات على أساس المهنة وجد

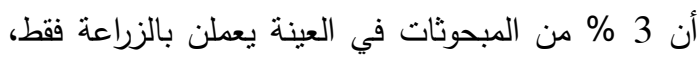

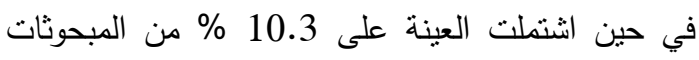
واللاتى يعملن في غير الزراعة ويمارسن الزراعة، بينما كانت النسبة الأكبر لفئة المبحوثات اللاتى يعملن ولاني يمارسن الزراعة حيث بلغت 84.8 \% من حجم الاكبر العينة

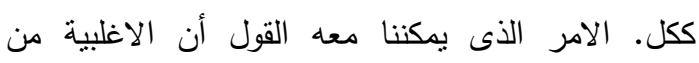

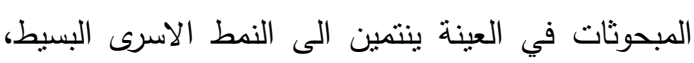

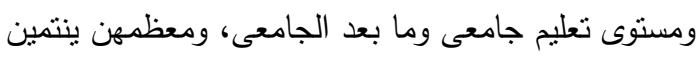
الى فئة يعملن ولا يمارسن الزراعة.

2.

جمعت بيانات هذا البحث باستخدام أسلوب المقابلة

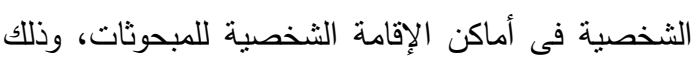

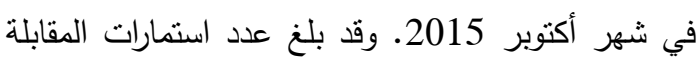

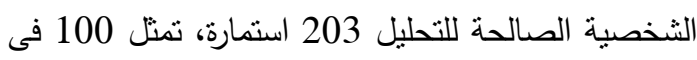
المئة من مجموع المبحوثات فى العينة المستهدفة. وقد ثم اعداد استمارة مقابلة شخصية لجمع البيانات. انشتملت هذه الاستمارة على مجموعة من الاسئلة مغلقة

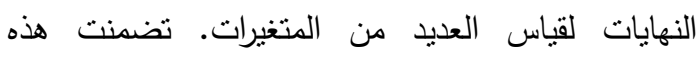

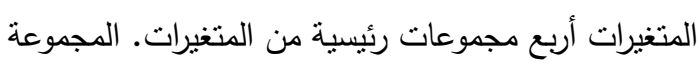

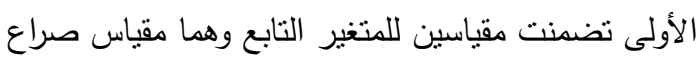
العمل مع الاسرة، ومقياس الاسرة مع العمل. كذلك للكئل المجموعة الثانية والتي تضمنت متغيرات نسق العمل وهى: ضغط العمل، والدعم في العمل، والدخل الثهرى الاسرى.

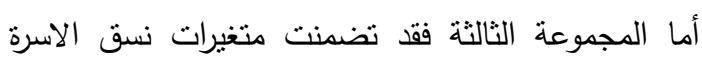

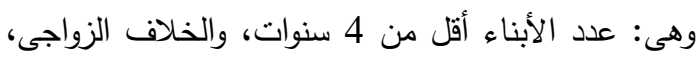

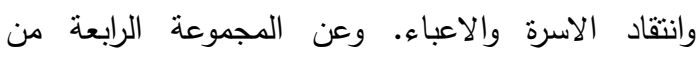

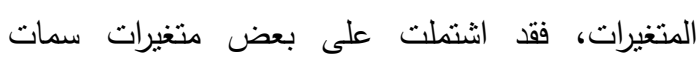
الثخصية وهى: العصابية، والانفتاح على الخبرة، وحيوية

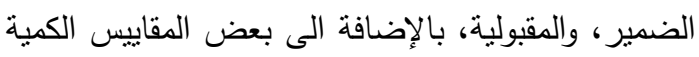

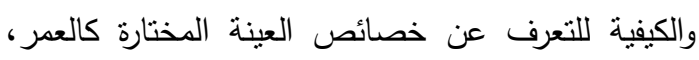

\section{الطرق والأساليب البحثية 1. مجتمع البحث و المبحوثات}

لتحقيق أهداف هذا البحث فقد تحدد المجتمع البحثى البحتئ

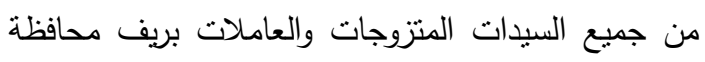

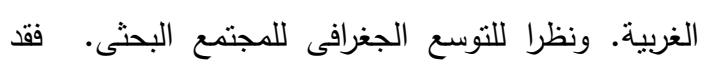
تقرر تمثيل مراكز محافظة الغربية الثمانية باختيار عينة تجمع بين أسلوب المعاينة العنقودية وأسلوب المعاينة بلئة العدية وذلك على ثلاثة مراحل: المرحلة الاولى فقد نم

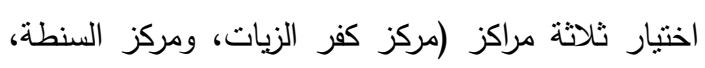

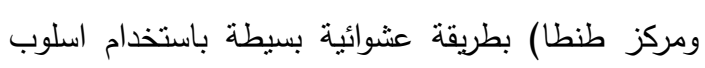

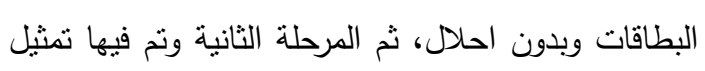
كل مركز من المراكز الثلاثة بعشر قرى عن كل مركز، البرات وذلك بشكل عشوائى بسيط باستخدام اسلوب البطاقات

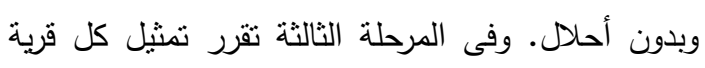

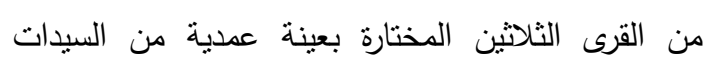
المتزوجات والعاملات. وبناءا عليه نم اختيار الاعداد الاتية من المبحوثات بشكل عدىى: (81 مبحوثة من قرى مركز كفر الزيات، و72 مبحوثة من قرى مركز السنطة،

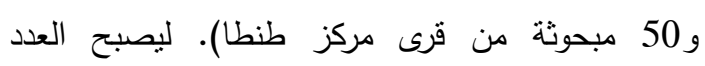
الاجمالى لعينة البحث من القرى المختارة هو 203 مبحوثة. وباستعراض أعمار المبحوثات وجد أن منوسط

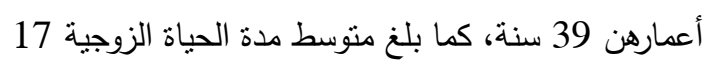
سنة، كذلك منتسط حجم الاسرة 4 أفراد، ومتوسط أعمار أكبر الأبناء في العينة 16سنة، بينما كان متوسط أعمار أصغر الأبناء 9 سنوات.

كما وجد أن النسبة المئوية للمبحوثات واللاتى ينتمين الى نمط أسرى بسيط هو 82.8 \%، بينما بلغت نسبة المبحوثات واللاتى ينتمين الى نمط الاسرة المركبة 17.2

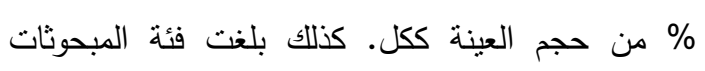
واللاتى ينتمين الى فئة الحاصلين على الثهادة الابتدائية

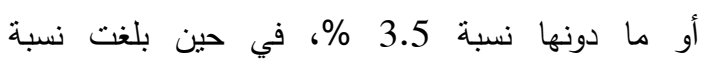

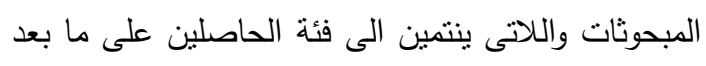

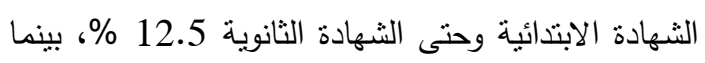




\section{Ebad-Allah}

فأما الاتجاه الأول Work-family conflict

(المقاييس الثلاثة الفرعية لصراع العمل مع (WFC) الاسرة): فتم قياسه بسؤال المبحوثات عن مدى موافقتهن على كل من البنود التالية: (عملى بيأخذنى من أنشطتى فئى الاسرية أكثر مما أريد، والوقت الذى يجب تكريسه لعملى العى لئى بيمنعنى من المشاركة فى أنشطتى ومسؤليانى الاسرية بشكل عادل، وأنشطنى الاسرية بتفونتى بسبب كمية الوقت التشى

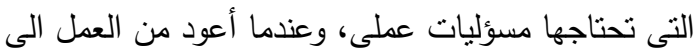
الهنزل فى كثير من الاحيان أكون مرتبكة جدا للمشاركة

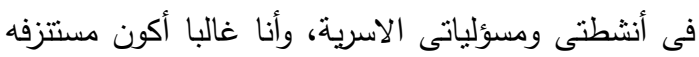

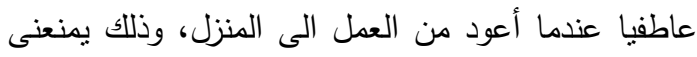
من المساهمة فى أسرتى، وبسبب كل ضغوط العمل، أحيانا عندما أعود الى المنزل أكون مرهقة لعمل الاشياء

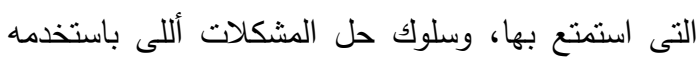

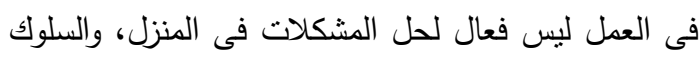

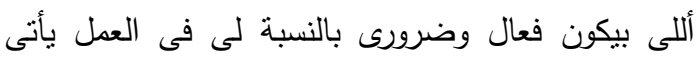

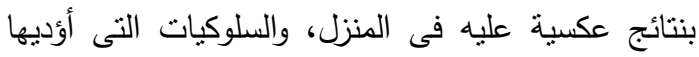

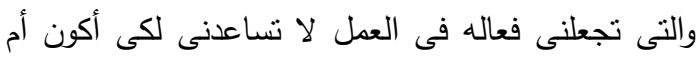

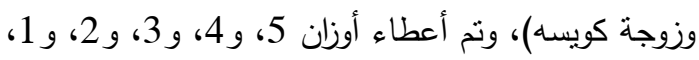

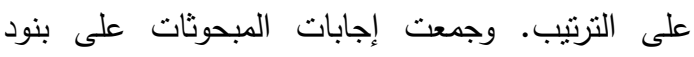
الدقياس لتعبر عن الدرجة الكلية للمقاييس الفرعية (لصراع العمل مع الاسرة). وحسب معامل ثبات ألفا كورنبخ

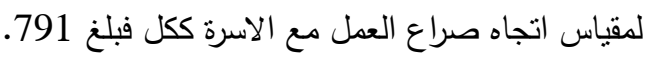
Family-work conflict وأما الاتجاه الثانى الجاه (المقاييس الثلاثة الفرعية لصراع الاسرة مع (FWC) العمل) فقد تم قياسه بسؤال المبحوثات عن مدى موافقتهن

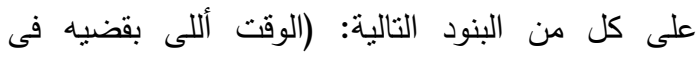

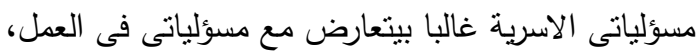

السلوك حيث بلغت 379. ، وهى قيمة معنوى عند مستوى احتمالى 01. ، كذللك وجود درجة من الارتباط البسيط بين بعد صراع الاسرة مع العمل والقائم

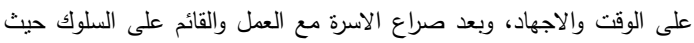

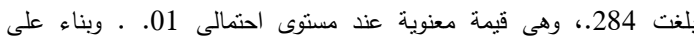
معاملات ثبات كلا الاتجاهين على مستوى المقياسين ككل. ووجود معاملات ارتباط بسيط متوسطة القوة بين المقاييس الفرعية لكلا الاتجاهين والتي اسفرت

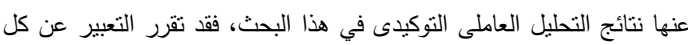
اتجاه بمقياس واحد أحادى البعد في هذا البحث.
وحجم الاسرة، وعمر أكبر الأبناء، وعمر أصغر الأبناء، ونمط الاسرة، والمسنوى التعليمى، والمهنة.

أما عن المجموعة الأولى وهى مقياس صراع العمل مع الاسرة، ومقياس صراع الاسرة مع العمل كمتغيرات تابعة في هذا البحث. فقد تضمنت استمارة المقابلة الثخصية على مقياس متعدد الابعاد متكامل ذو اتجاهين لقياس ظاهرة صراع العمل والاسرة، والمقنن من قبل (Carlson, Kacmar, and Williams, 2000)، حيث تم تطبيقه على خمس عينات. أسفرت النتائج عن بناء هذا المقياس والتأكد من صدق محتواه وثبات نتائجه، وذلك وفقا لمعايير متعددة، والتي اسفرت عن مقياس مكون من 18 بند، تعبر عن ستة مقاييس فرعية لقياس ستة أبعاد لظاهرة العمل والاسرة. تسعة بنود منه وتشتمل على 3 مقاييس فرعية لثلاثة أبعاد لصراع العمل مع الاسرة وهى: (صراع قائم على الوقت، وصراع قائم على الاجهاد،

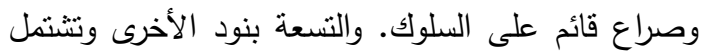

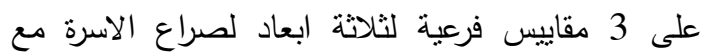

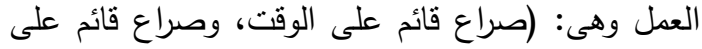
الاجهاد، وصراع قائم على السلوك). وقد تم استخدام هذا

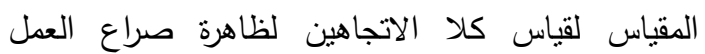
والاسرة. هذا ولم تتوصل النتائج الى ثبات وصدق بعد الثد

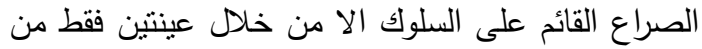
العينات الخمس والتي تضمنتها الدراسة. وبناء عليه

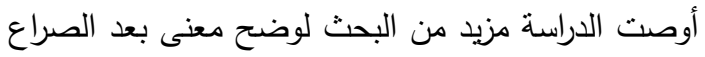
القائم على السلوك لدى المبحوثين، وكذلك طريقة قباسه. 1

1افي هذا البحث وبناء على نتائج النحليل العاملى التوكيدى والتي سوف يتم

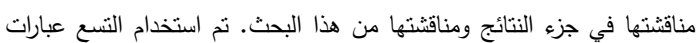

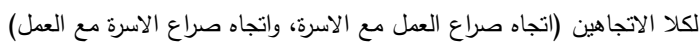

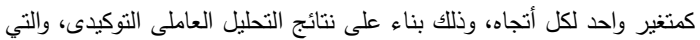

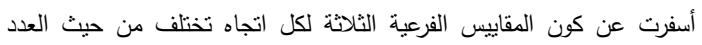
والمحتوى عن المقياس الاصلى ذو الابعاد الستة، وكذلك ونظرا لارتفاع معامل

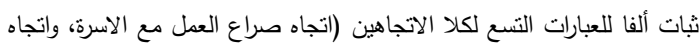

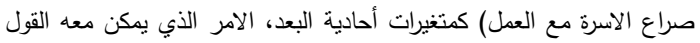

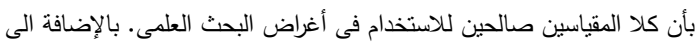

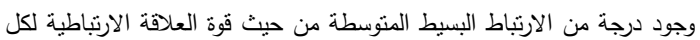

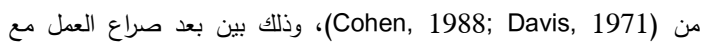

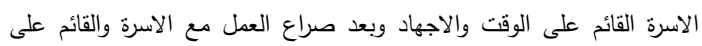


ومرؤوسيها في العمل من جهة أخرى بأنها داعمه لها أم

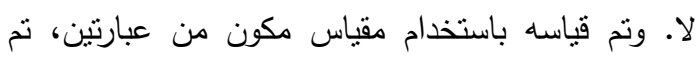

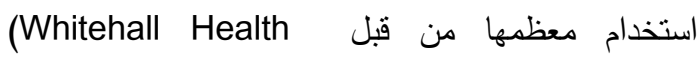
Survey, 1989) كما طلب من المبحوثات الاختيار من هن

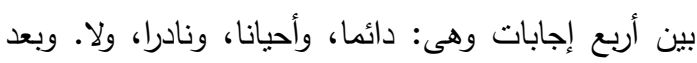

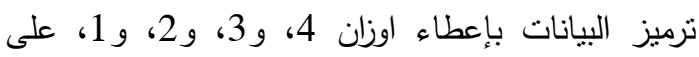

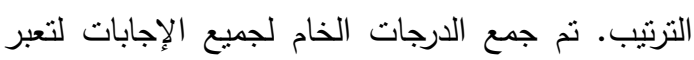

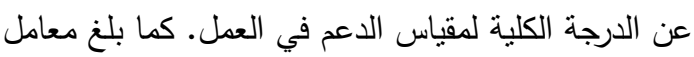
ثبات ألفا كورنبخ لمقياس الدعم في العمل 606. كما تضمنت الاستمارة مقياس للاخل الثهرى الاسلى:

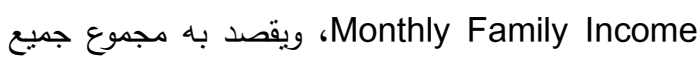
الموارد المالية الثهرية للأسرة من مصادرها المختلفة. ونم

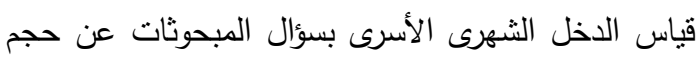

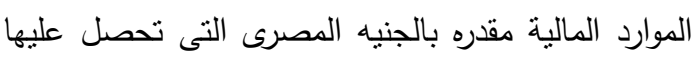
الأسرة من كل من عملها، وعمل الزوج، وعمل الأولاد، و

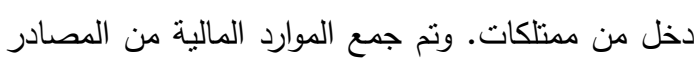
الأربعة. وكان المنوسط الحسابى للاخل الثهري لكران للأسرة

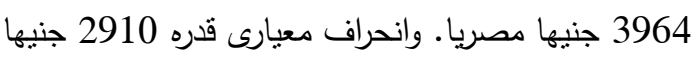

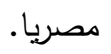

أما المجموعة الثاثثة: وهى متغيرات نسق الاسرة

كمقياس عدد الأبناء أقل من 4 سنوات : Children less than 4 years مع المبحوثة وتجمعهم مكان واحد للمعيشة. وتم قياس عدد لإند

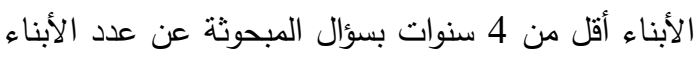
الذين يعيشون مع المبحوثة فى مكان معيشة واحد، وكان

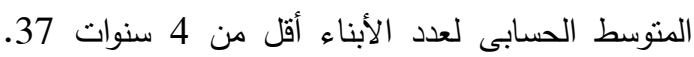
أبن، بانحراف معيارى قدره 84. أبن.

كذلك تضمنت الاستمارة على مقياس لمتغير الخلاف

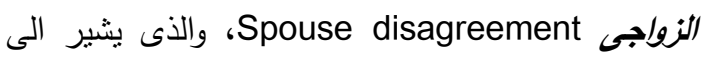
مدى الاختلاف بين الزوجة والزوج حول أمور الاسرة

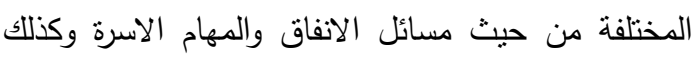
أوقات التزفيه. ونت قياسه بمقياس مكون من ثلاثة بنود.

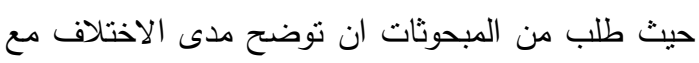
الزوج في كل مسألة من المسائل الثلاث، وذلك بالاختيار
والوقت أللى بقضيه مع أسرتى غالبا بيكون سبب فى عدم

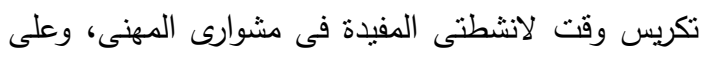

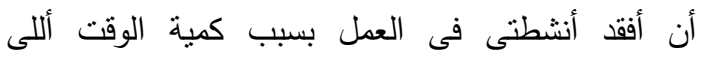
تحتاجها مسؤلياتى الاسرية، وبسبب الضغوط فى المنزل،

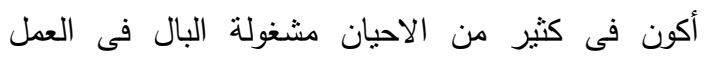

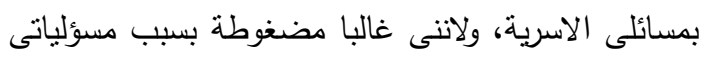

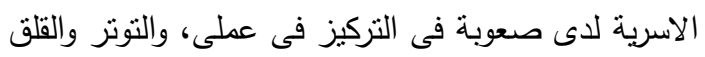

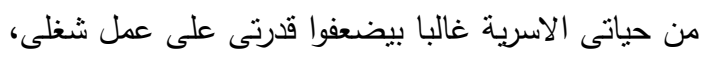

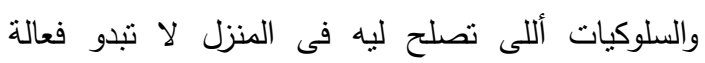

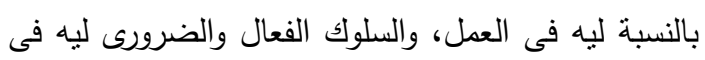

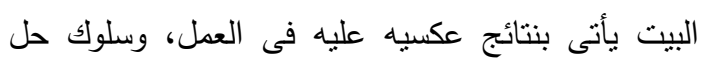

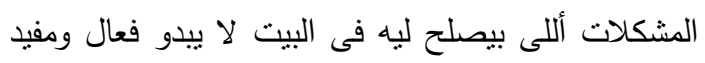

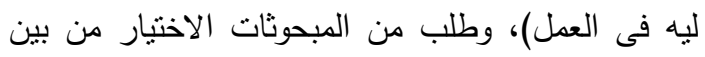

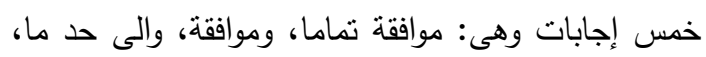

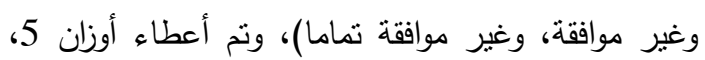

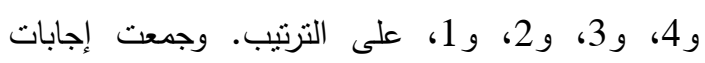

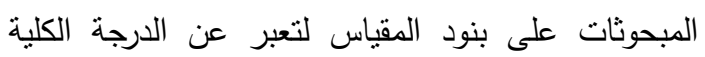

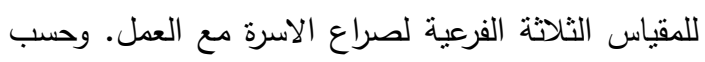

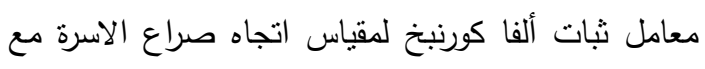

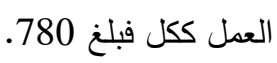

أما المجموعة الثانية: وهى مجموعة متغيرات نسق العمل كمتغير ضنط العقل Pressure at Work ويثنير الى حجم الاجهاد النفسى والمرتبط بالعمل. وتم قياسه باستخدام مقياس مكون من أربع عبارات نم استخدام معظمها من قبل National Survey of Midlife Development in the United States (MIDUS),

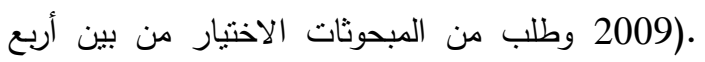

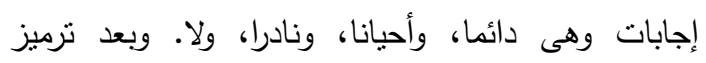

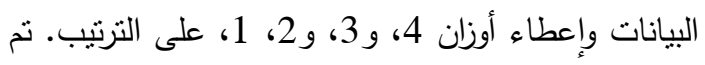

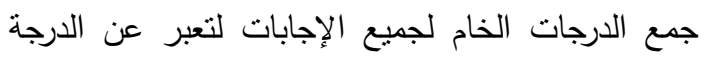

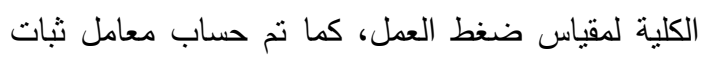
ألفا كورنبخ فوجد 323.

Support at Work وأيضا متغير الدعم في العدل ويقصد به إدراك العلاقة بين المبحوثة من جهة وزملائها 
حسب معامل ثبات ألفا كورنبخ لمقياس العصابية وكان

Openness to كنلك مقياس الانفتاح على الخبرة experience والاعجاب الثديد بالخبرات الجديدة، والذكاء المتوقد والانفتاحية، والحساسية الجمالية، وقيم التسلطية، والانفتاح على مشاعر الاخرين، وخبراتهم الانفعالية، والانخراط في استجابة عاطفية. (Colman, 2003) ، وقد ثم قياس الاس متغير الانفتاح على الخبرة من خلال عثر عبارات تم تعريبها من مقياس Goldberg، (1999). وطلب من المبحوثات الاختبار من بين خمس إجابات وهي: نتطبق على تماما، وتتطبق على كثيرا، وتتطبق على أحيانا،

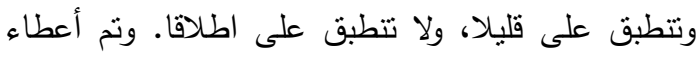

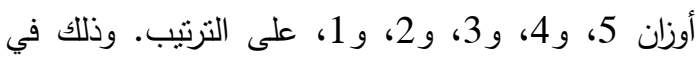

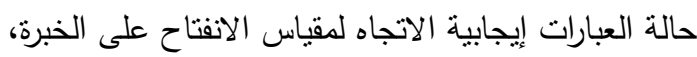

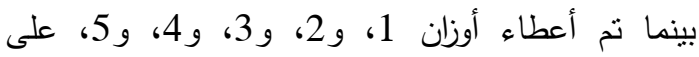

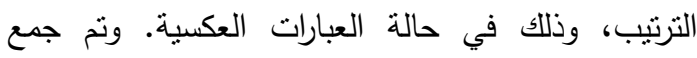
الدرجات الخام لجميع الإجابات لتعبر عن الدرجة الكلية

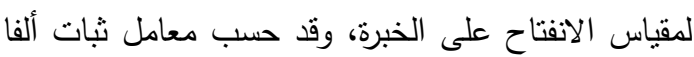
كورنبخ لمقياس الانفتاح على الخبرة وكان 307.

وعن متغير حيوية الضمير Conscientiousness كأحد متغيرات سمات الثخصية، ويقصد به التتظيم والسلوك الموجه نحو هدف من قبل الفعالية، ومراعاة القانون، وسمات الضبط والوفاء بالواجبات على الوجه الاكمل، والكفاح من أجل الإنجاز، وتهذيب النفس،

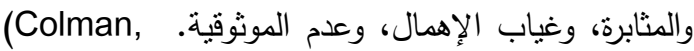
(2003 وقد نم قياس متغير حيوية الضمير من خلال

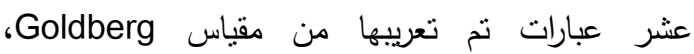

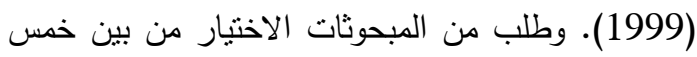
إجابات وهي: تتطبق على تماما، وتنطبق على كثيرا،

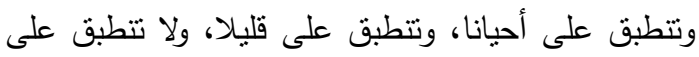

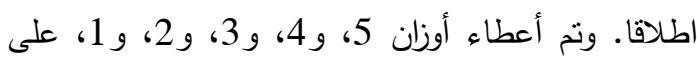

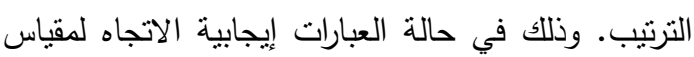
حيوية الضمير، بينما نم أعطاء أوزان 1، و2، و3، و4،
من بين أربع إجابات وهى: دائما، وأحيانا، ونادرا، ولا،

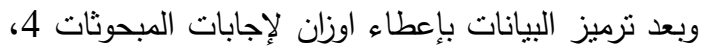
و3، و2، و 1، على التزتيب. تم جمع الدرجات الخام لجميع الإجابات لتعبر عن الدرجة الكلية لمقياس الخلاف الزواجى. كم تم حساب معامل ثبا الفا كورنبخ فكانت قيمته الإنه

\section{.555}

كذلك اشتملت الاستمارة على متغير انتقاد الاسرة والأعباء Family Criticism and Burden، ويثير الى النقد السلبي والذي يوجه الى الام من قبل أفراد الاسرة

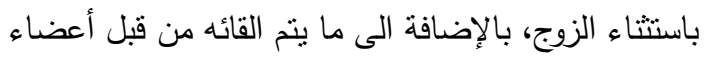
الاسرة أيضا من أعباء إضافية. وتم قياس متغير النتاد الاسرة والاعباء بمقياس مكون من أربع عبارات معظم هذه

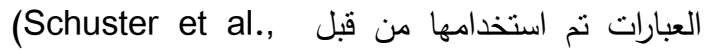
(1990، وطلب من المبحوثات الاختيار من بين أربع

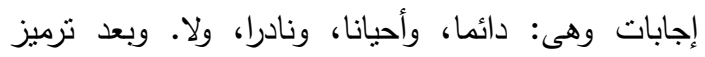

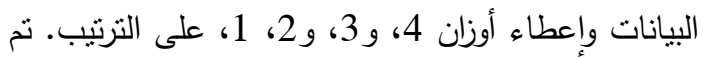
جمع الدرجات الخام لجميع الإجابات لتعبر عن الدرجة

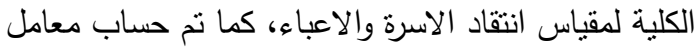
ثنات ألفا كورنبخ فوجد 458.

\section{أما المجموعة اللربعة: فقد نضمنت متغير العصابية} Neuroticism ، والذي يشير الى العصبية، وسرعة التهيج، إضافة الى السمات الانفعالية والسلوكية السلبية كالقلق والاكتئاب والتوتر وتقلب المزاج وعدم الاستقرار الوجداني والاثفاق على النفس. (Colman, 2003) ، وقد تم قياس متغير العصايية من خلال عشر عبارات نم

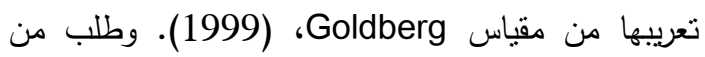

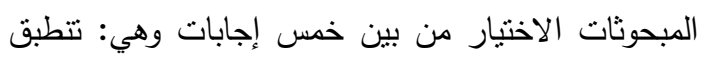
على تماما، وتتطبق على كثيرا، وتتطبق على أحيانا،

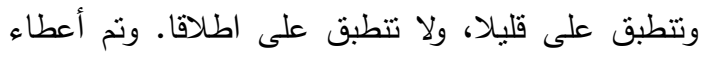

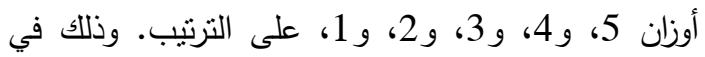
حالة العبارات إيجابية الاتجاه لمقياس العصابية، بينما نم

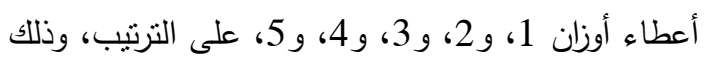

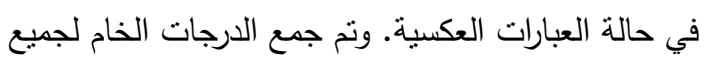
الإجابات لتعبر عن الدرجة الكلية لدقياس العصابية، وقد 
والاسرة، و تدويرهم تدويرا متعامدا باستخدام طريقة

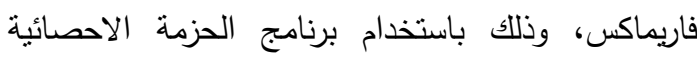

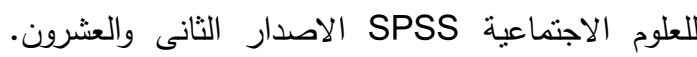

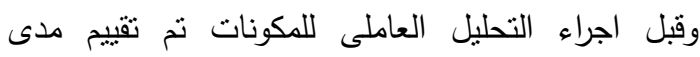

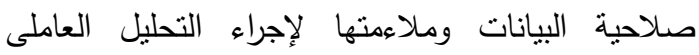

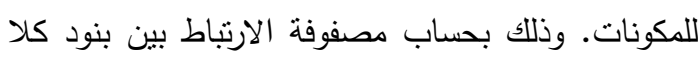

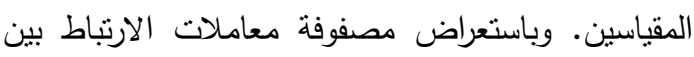

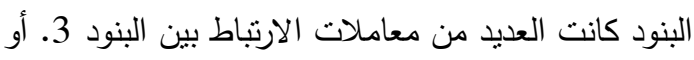
Kaiser-Meyer-Oklin أكثر. كذلك حسبت قيمة فكانت 782. لبنود مقياس صراع العمل مع الاسرة،

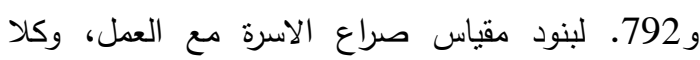

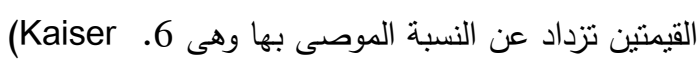
(ختبار ،(Bartlett 1954) Bartlett's of Sphericity وكانت نتائجه معنوية فى كلا العينتين، والتى ندعم نتائج مصفوفة الارتباط وتؤكد قابلية البيانات لإجراء التحليل

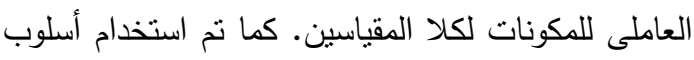

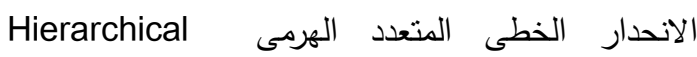
Multiple Regression Technique هذا الأسلوب نم النأكيد من مدى صلاحية البيانات لاجراء

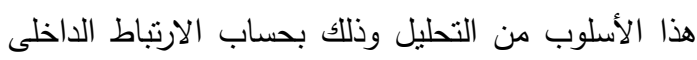

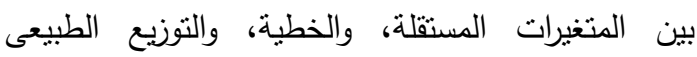

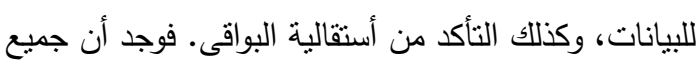

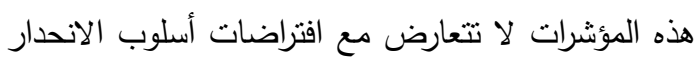

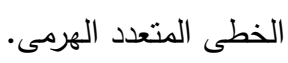

\section{نتائج البحث ومناقشتها}

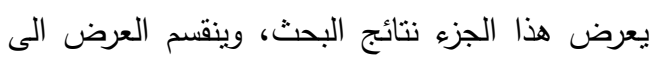

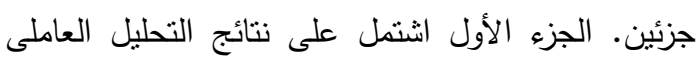

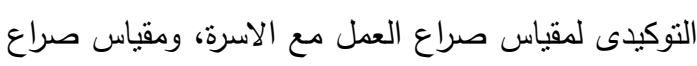

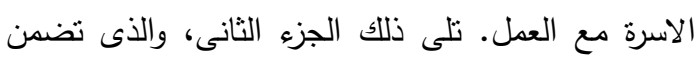

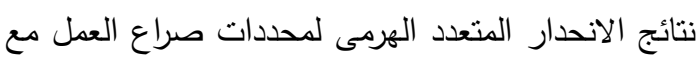

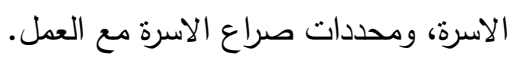

و5، على الترتيب، وذللك في حالة العبارات العكسية. وتم

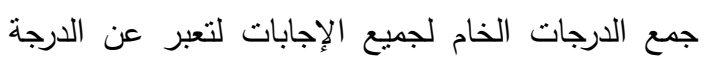

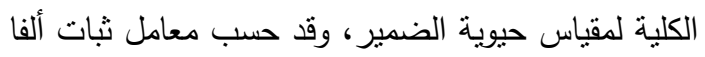
كورنبخ لمقياس حيوية الضمير وكان 413. كما تضدنت استمارة المقابلة مقياس لمتغير المقبولية Agreeableness

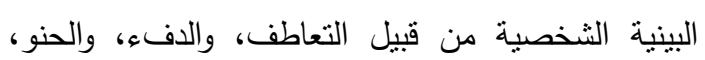
والتسامح، والتعاون، وحب الغير. (Colman, 2003)

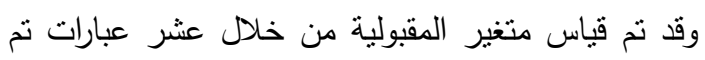

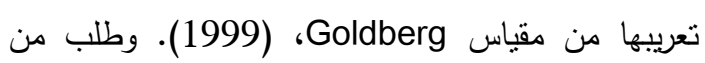
المبحوثات الاختيار من بين خمس إجابات وهي: تنطبق على تماما، وتتطبق على كثيرا، وتتطبق على أحيانا، وتنطبق على قليلا، ولا تنطبق على اطلاقا. وتم أعطاء

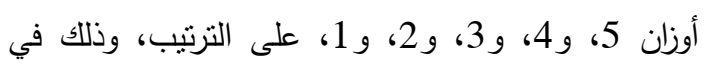

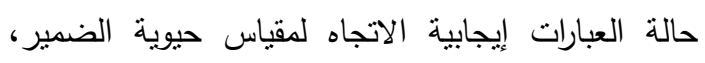

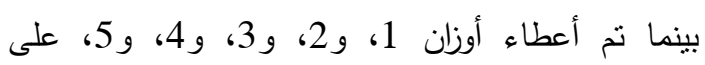

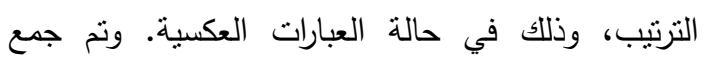
الدرجات الخام لجميع الإجابات لتعبر عن الدرجة الكلية لمقياس المقبولية، وقد حسب معامل ثبات ألفا كورنبخ لمقياس المقبولية وكان 514.

\section{3. التحليل الاحصائى}

بعد ترميز البيانات نم ادخالها الى الحاسب الألى. وتم اجراء التحليل، وذلك باستخدام برنامج الحزمة الاحصائية للعلوم الاجتماعية SPSS الاصدار الثانى والعشرين. كما لئل نم حساب النكرارات والنسب المئوية للمتغيرات الكيفية

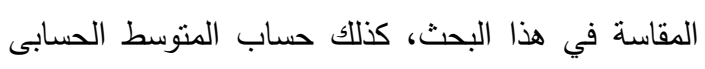

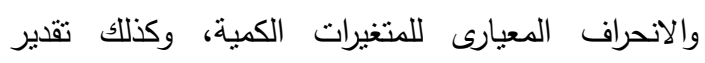
معاملات ثبات ألفا كورنبخ للدقاييس التي تم استخدامها في التحليل. كما تم حساب المتوسط الحسابى والانحراف

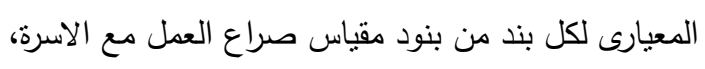
ومقياس صراع الاسرة مع العمل. كما نم اجراء التحليل

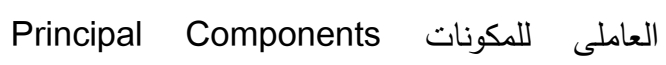
على بنود مقياسى صراع العمل Analysis (PCA) 
المنزل أكون مرهقة لعمل الأشياء الني استمتع بها). وقد بلغت متوسطات درجات المبحوثات على هذه البنود البناء 3.07، 3.23، 3.50، على الترتيب.

ويتضح من منوسطات درجات اجات كلا

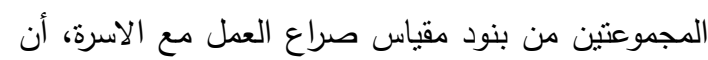
بنود المجموعة الأولى تضمنت ستة بنود تعبر عن الابعاد الادي

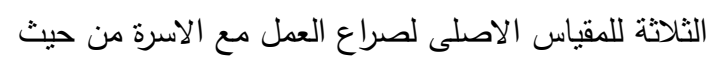

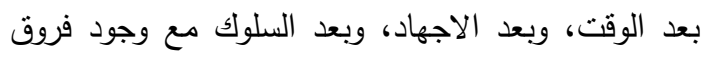
طفيفة بين منوسطات الاجابات. أما المجموعة الثانية من

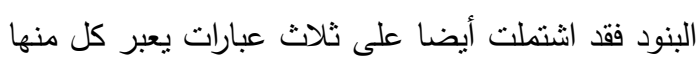

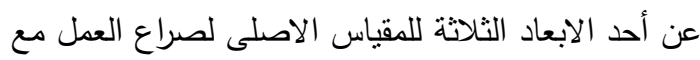
الاسرة. الامر الذى يمكن معه القول بوجود تباين بين

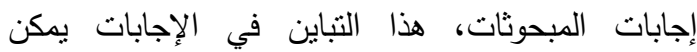
تصنيفه الى مجموعتين.

2.1 نتائج التحلِل العاملى التوكيدى لمقيّاس صراع العمل مي الاسبرة

تشير نتائج التحليل العاملى لعينة المبحوثات جدول

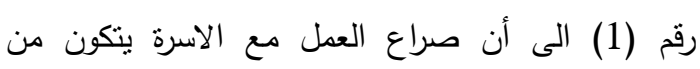
عاملين، تجاوز الجذر الكامن لكل منها الواحد الصحيح. وهذه العوامل تفسر 38.654 \%، 14.830 \% من التباين فى بنود المقياس على الترتيب. وبفحص الثكل

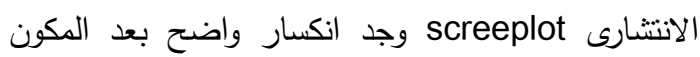
النانى. وباستخدام اختبار الانتشار ل Catell (1966)

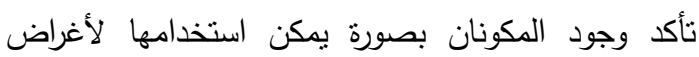

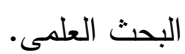

وبفحص قيم معاملات التتبع الواردة فى المصفوفة

يتضح أن هناك ستة بنود تشبعت على المكون الاول

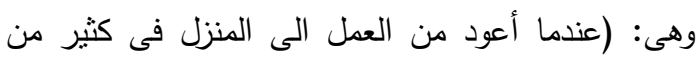

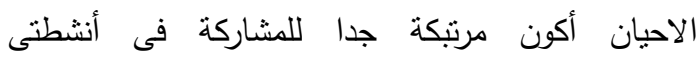
ومسؤولياتي الاسرية، وأنا غالبا أكون مستتزفه عاطفيا

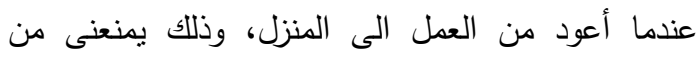

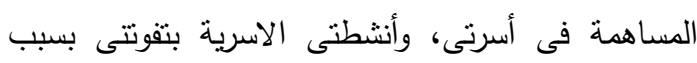

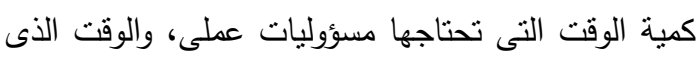
يجب نكريسه لعملى بيمنعنى من المشاركة فى أنشطتى
1. نتائج وصف إجابات المبحوثات والتحليل العاملى التوكيدى لمقياس صراع العمل مع الاسرة 1.1 نتائج وصف إجابات المبحوثات على بنويد

\section{مقياس صراع العمل مع الاسرة}

يعرض جدول رقم (1) المتوسطات والانحرافات

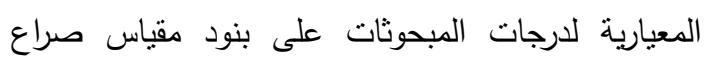

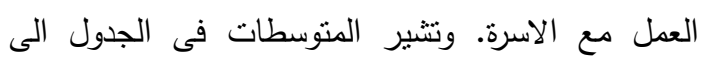
وجود مدى من المتوسطات على بنود المقياس يتراوح بين 2.06 درجة وذللك على بند (السلوكيات التي أوديها والتي تجعلنى فعاله في العمل لا تناعدنى لكى أكون أم وزوجة

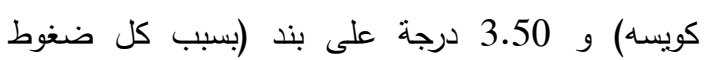

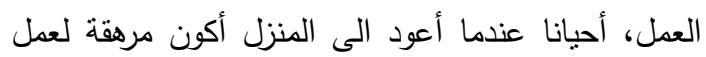

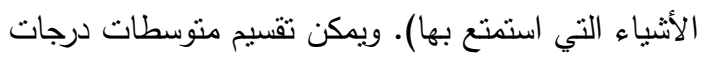

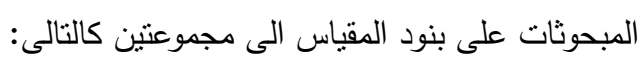
المجموعة الاولى وتتضنمن متوسطات درجات المبحوثات أقل من ثلاث درجات وتشمل عبارات: (السلوكيات التي أوديها والتي تجعلنى فعاله في العمل لات ألات نساعدنى لكى أكون أم وزوجة كويسه، والسلوك أللى بيكون فعال وضرورى بالنسبة لى في العمل يأني بنتائج عكسيه عليه في المنزل، وأنا غالبا أكون مستنزفه عاطفيا عندما أعود من العمل الى المنزل، وذللك يمنعنى من المساهمة

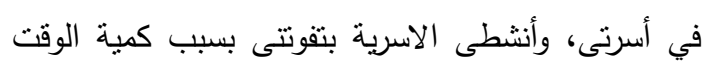

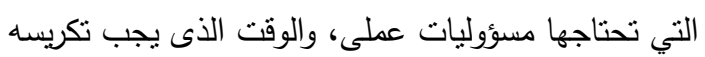
لعملى بيمنعنى من المشاركة في أنشطى ومسؤولياتي

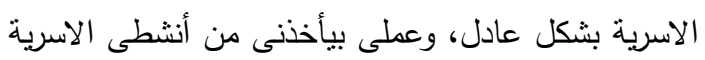

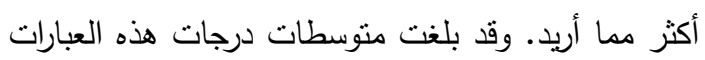
الست 2.06، و2.44، و و2.49، و و 2.47، و و 2.81، و2.94، على الترتيب. والمجموعة الثانية متوسطات درجات المبحوثات أكبر

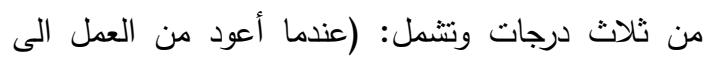
المنزل في كثير من الأحيان أكون مرنبكة جدا للمشاركة

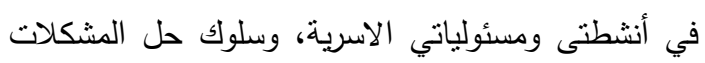

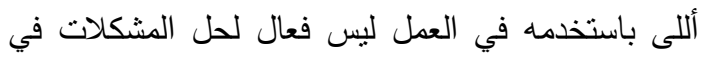

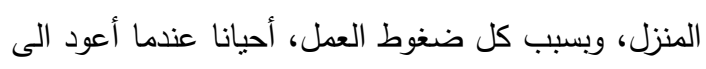


ومسؤولياتي الاسرية بشكل عادل، وعملى بيأخذى من على هذا المكون نجد أنها تتعلق باستتزاف الوقت

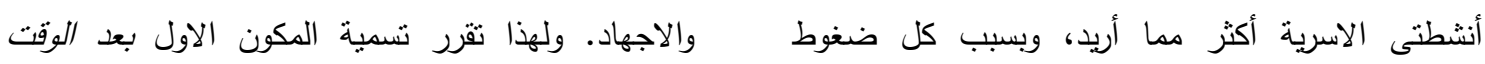

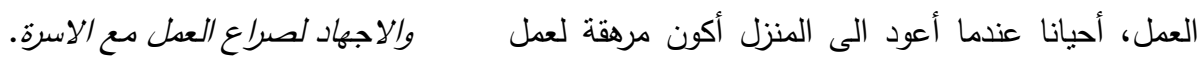

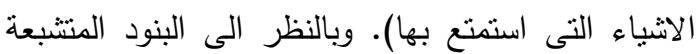

جدول 1. المصفوفة العاملية الدوارة لصراع العمل مع الاسرة

\begin{tabular}{|c|c|c|c|c|c|}
\hline \multirow[t]{2}{*}{ الثيوع } & \multicolumn{2}{|c|}{ معاملات التشبع } & \multirow{2}{*}{ 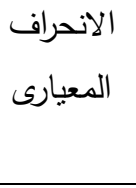 } & \multirow[t]{2}{*}{ المنوسط } & \multirow[b]{2}{*}{ البند البن } \\
\hline & 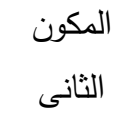 & 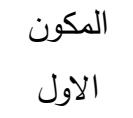 & & & \\
\hline .538 & -.050 & .732 & 1.21 & 3.07 & والاحيان أكون مرنبكة جدا العود من العمل الى المنزل فى كثير من ألثنير منى \\
\hline .537 & .065 & .730 & 1.16 & 2.49 & ألى أسلا غالبا أكون مستنزفه عاطفيا عندما أعود من المنزل، وذلك يمنعنى من المساهمة \\
\hline .644 & .341 & .726 & 1.17 & 2.77 & تحتناجها مسؤليات الاسرية بتفوتتى بسبب كمية الوقت التى \\
\hline .539 & .206 & .705 & 1.12 & 2.81 & 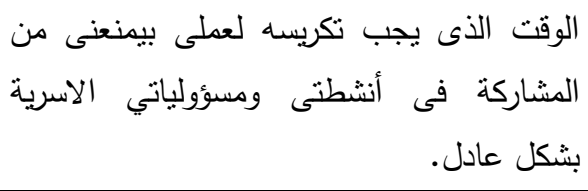 \\
\hline .459 & .150 & .661 & 1.09 & 2.94 & أريد. عملى بيأخذنى من أنشطتى الاسرية أكثر مما \\
\hline .367 & .185 & .577 & 1.10 & 3.50 & 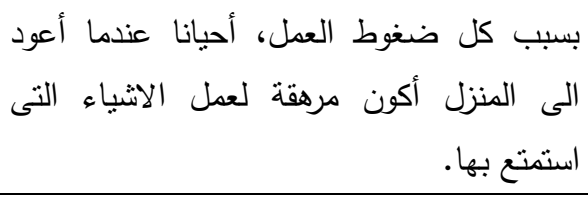 \\
\hline .624 & .799 & .210 & 1.09 & 2.44 & 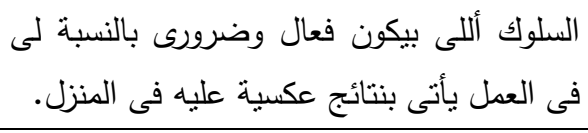 \\
\hline .683 & .774 & .160 & 1.07 & 2.06 & 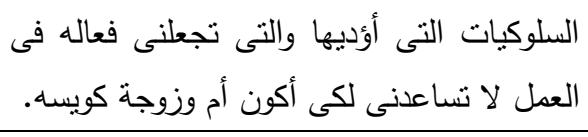 \\
\hline .624 & .648 & .049 & 1.07 & 3.23 & لبس فعال لحل المشكلات فى المنزل. أللى باستخده فى العمل \\
\hline 53.484 & 14.830 & 38.654 & - & - & \% للتباين المفسر \\
\hline
\end{tabular}

ملاحظة: قيم التثبعات الكبرى لكل بند من بنود المقياس تم تحديدها بالخط العريض. 
وبناء عليه فقد تقرر استخدام بنود المقياس ككل كبعد واحد

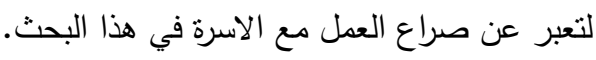

2. نتائج وصف إجابات المبحوثات والتحليل العاملى التوكيدى لمقياس صراع الاسرة مع العمل 1.2 نتائج وصف إجابات المبحوثات على بنود مقياس صراع الاسرة مع العمل

يعرض جدول رقم (2) المتوسطات والانحرافات

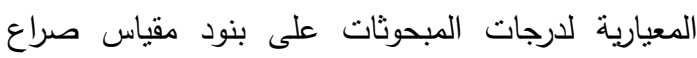

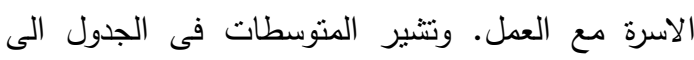
وجود مدى من المتوسطات على بنود المقياس ينراوح بين 2.28 درجة وذللك على بند (السلوك الفعال والضرورى ليه في البيت بأتي بنتائج عكسيه عليه في العمل) و 3.16

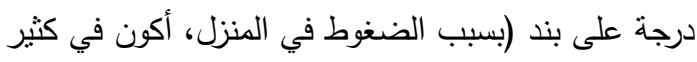
من الأحيان مشغولة البال في العمل بمسائلى الاسرية).

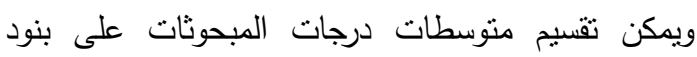

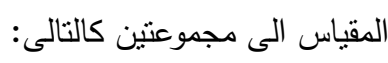

المجموعة الاولى وتتضمن منوسطات درجات

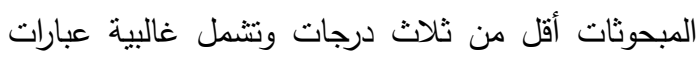
المقياس وهى: (السلوك الفعال والضرورى ليه في البيت داتل

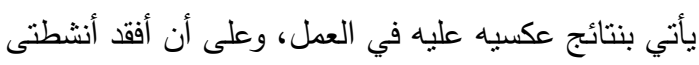
في العمل بسبب كمية الوقت أللى تحتاجها مسؤولياتي

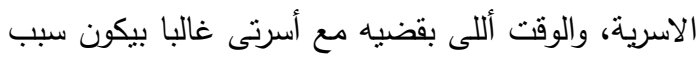

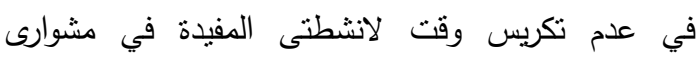

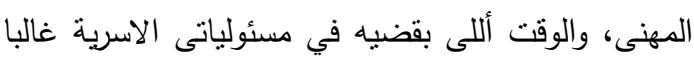

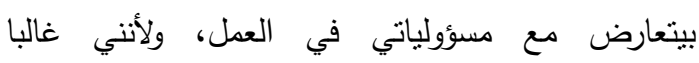

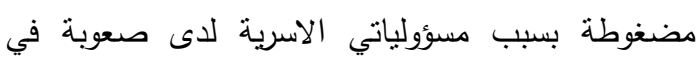

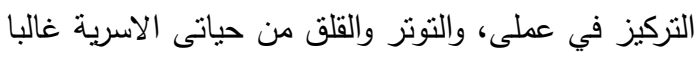
بيضعفوا قدرتى على عمل شغلى، وسلوك حل المشكلات

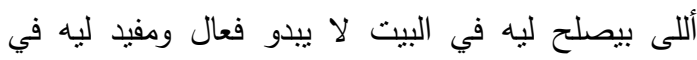

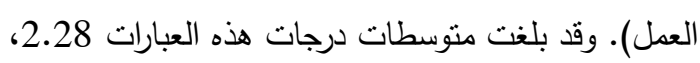
و 2.41، و2.45، و2.50، و2.59، و 2.73، و 2.80،

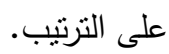

كذللك أظهرت النتائج وجود ثلاثة بنود تثبعت على

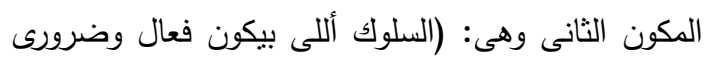

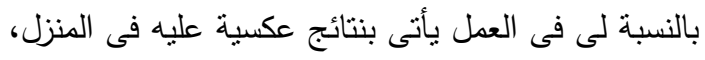

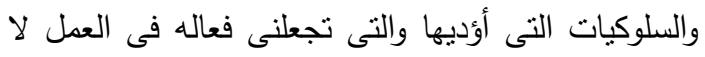

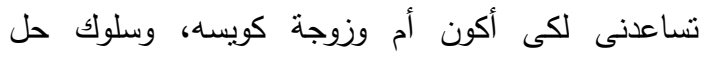

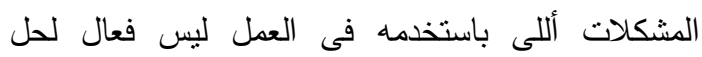

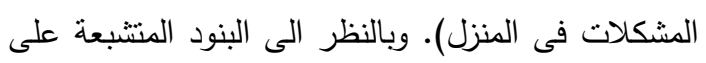
هذا المكون نجد أنها تتعلق بناثير العمل على السلوك النئل

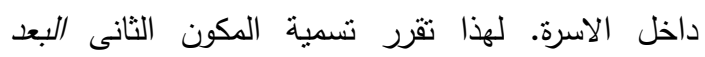
السلوكى لصراع العقل مع الاسرة.

كما حسبت معاملات ثبات Cronbach's Alpha

للبنود المنتبعة لكلا المكونين فكانت قيمتها و628. ، على الترتيب. وهذه القيم تقترب من 7. فأكثر

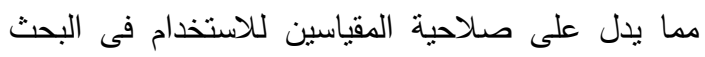

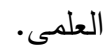

يتضح من نتائج التحليل العاملى التوكبدى لمقياس

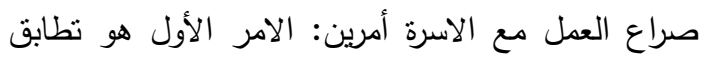

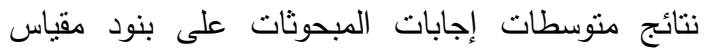

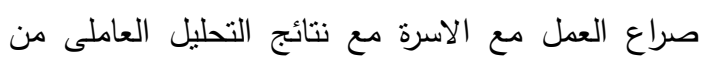
حيث تباين الإجابات في مجموعتين وبعدين، مع الاستلاف دئل مكونات كلا المجموعتين والبعدين من حيث المحتوى من في الإبن

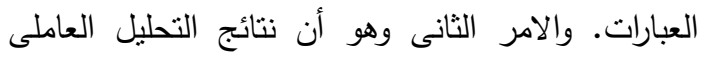
أكدت التمايز بين بعدين مقارنة بالمقياس الاصلى والثي المكون

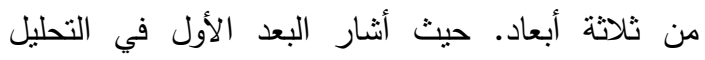

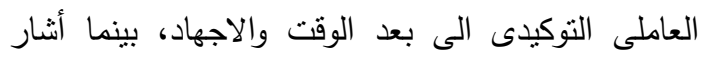
البعد الثانى الى البعد السلوكى. وهذا بعنى أن التعلى التحليل

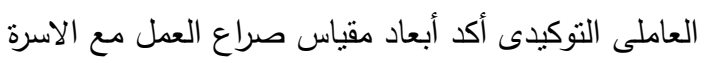

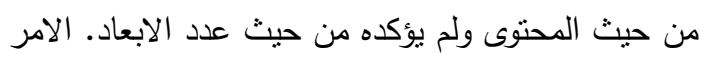
الذى قد يرجع الى أختلاف خصائص وحجى وحم العينة،

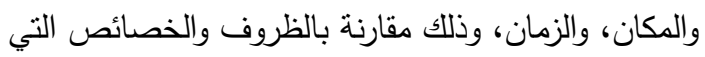

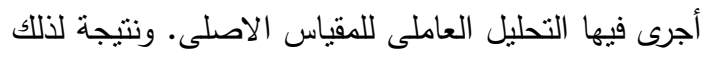

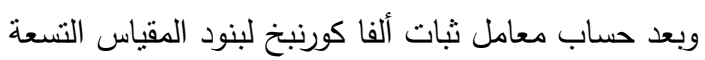
ككل فوجدت 791. ، وهى قيمة مرتفعة وتدل على ثبات المقياس ككل وصلاحية استخدامه في البحث العلمى، ونى ونى 
جدول 2. المصفوفة العاملية الدوارة لصراع الاسرة مع العمل

\begin{tabular}{|c|c|c|c|c|c|}
\hline \multirow[t]{2}{*}{ الثيوع } & \multicolumn{2}{|c|}{ معاملات التشبع } & \multirow{2}{*}{ 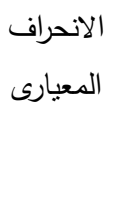 } & \multirow[t]{2}{*}{ المنوسط } & \multirow[b]{2}{*}{ البند } \\
\hline & 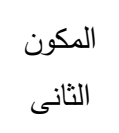 & 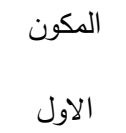 & & & \\
\hline .659 & -.007 & .812 & 1.09 & 2.59 & 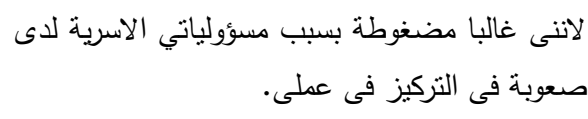 \\
\hline .560 & .107 & .741 & 1.17 & 3.16 & 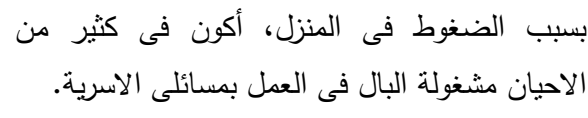 \\
\hline .464 & .100 & .715 & 1.06 & 2.45 & 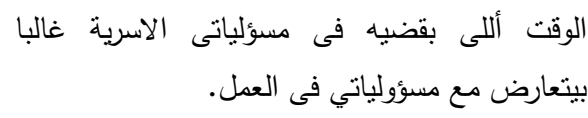 \\
\hline .514 & .213 & .685 & 1.02 & 2.41 & 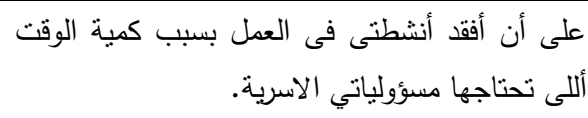 \\
\hline .521 & .169 & .660 & 1.10 & 2.50 & 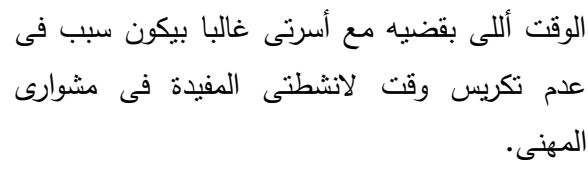 \\
\hline .337 & .048 & .579 & 1.17 & 2.73 & على عمل شغلى. التوتر والقلق حياتى الاسرية غالبا بيضعفوا قدرتى \\
\hline .258 & .354 & .364 & .99 & 2.28 & عكسيه عليه فى العمل. الضلورى ليه فى البيت بأنى بنتائج \\
\hline .736 & .855 & .072 & 1.17 & 2.80 & سيدو فعال ومفيد ليه فلى العطل. أللى بيصلح ليه فى البيت لا \\
\hline .660 & .809 & .071 & 1.22 & 3.05 & بالنسبة ليه فى العطل. أللى تصلح ليه فى المنزل لا تبدو فعالة \\
\hline 52.325 & 14.958 & 37.367 & - & - & \% للتباين الدفسر \\
\hline
\end{tabular}

ملاحظة: قيم التثبعات الكبرى لكل بند من بنود المقياس نم تحديدها بالخط العريض.

والمجموعة الثانية منوسطات درجات المبحوثات أكبر درجات المبحوثات على هذه البنود 3.05، 3.16، على

من ثلاث درجات وتتشمل بنود: (السلوكيات أللى تصلح لى الترتيب.

يتضح من متوسطات درجات كلا المجموعتين أن

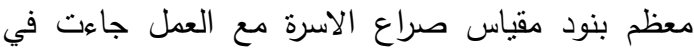

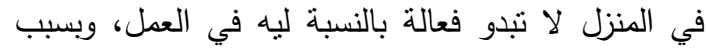

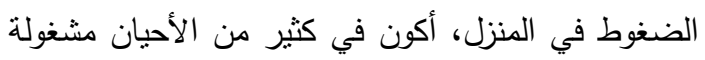
المجموعة الأولى لمتوسطات إجابات المبحوثات، وبالنظر الانس

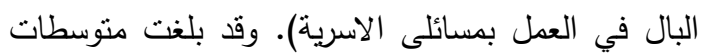




\section{Ebad-Allah}

والسلوك الفعال والضرورى ليه فى البيت بأتى بنتائج

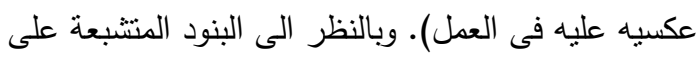
هذا المكون نجد أن غالبيتها تتعلق باسنتزاف الوقت لوبل والاجهاد، ولهذا تقرر تسمية المكون الأول ببعد الوقت

\section{والاجهاد لصراع الاسرة مع العقل.}

كذللك أظهرت النتائج وجود بندان قد تشبعا على المكون الثانى وهما: (سلوك حل المشكلات أللى بيصلح

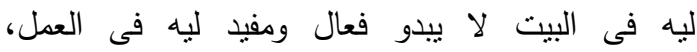

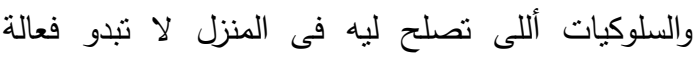

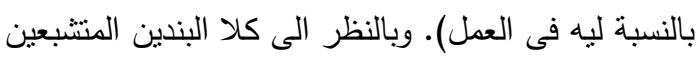

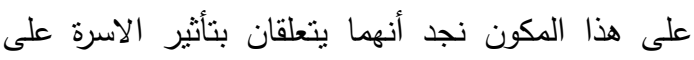

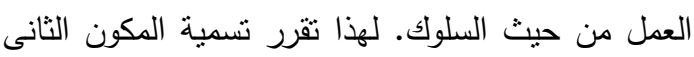

\section{بالبعد السلوكى لصراع الاسرة مع العمل.}

كما حسبت معاملات ثبات Cronbach's Alpha

للبنود المتشبعة لكلا المكونين فكانت قيمتها 796. و637. ، على الترتيب. وهذه القيم نقترب من 7. فأكثر مما يدل على صلاحية المقياسين للاستخدام فى البحث

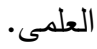

يلاحظ من نتائج التحليل العاملى التوكيدى لمقياس

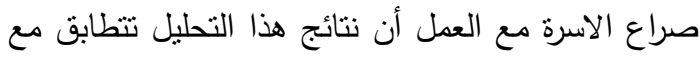
نتائج منوسطات إجابات المبحوثات على بنود مقياس صراع العمل مع الاسرة من حيث عدد المجموعات وعدد

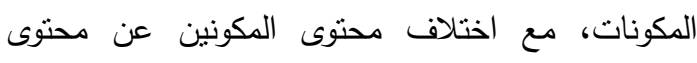
المجموعنين من منوسطات إجابات المبحوثات. الامر الاخر الذى يمكن ملاحظته هو اختلاف نتائج التحليل العاملى التوكيدى عن نتائج مكونات المقياس الاصلى من لإن

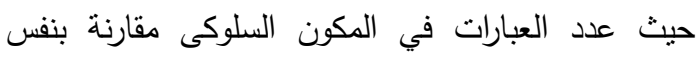

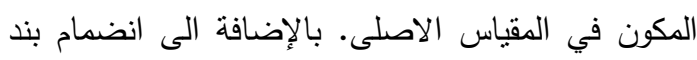
(السلوك الفعال والضرورى لبه في البيت ياتى بنتائج عكسية عليه في العمل) كاحد البنود المعبرة عن البعد السلوكى في المقياس الاصلى الى بعد الوقت والاجهاد

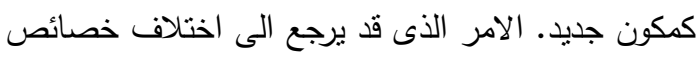
العينة وحجمها، بالإضافة الى اختلاف الزمان والمكان. وبناء عليه، وبعد حساب معامل ثبات ألفا كورنبخ لبنود
الى مكونات هذه المجموعة من البنود نجد أنها تنتل أبعاد

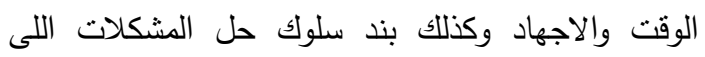
بيصلح ليه في البيت لا ييدو فعال ومفيد ليه في العمل، ولاكل والذى يمنل جانب من البعد السلوكى. أما المجموعة الثنانية

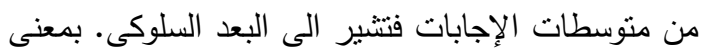

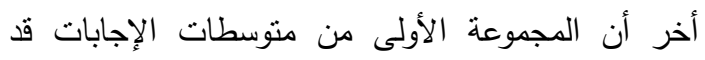

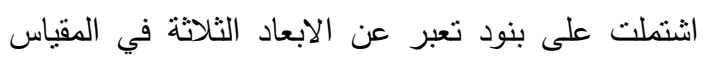
الاصلى وهى بعد الوقت، وبعد الاجهاد، وبعد السلوك. أما الهجموعة الثانية فقد أثنتملت منوسطات إجابات بنودها على البعد السلوكى فقط.

2.2 نتائج التحليل العاملى التوكبدى لمقياس صراع

\section{الاسرة مع العمل}

تثنير نتائج التحليل العاملى لعينة المبحوثات جدول

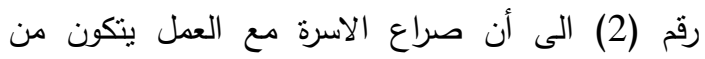
عاملين، تجاوز الجذر الكامن لكل منها الواحد الصحيح. وهذه العوامل تفسر 37.367 \% ، 14.958 \% من التنباين فى بنود المقياس على التزتيب. وبفصص الثنكل الانتشارى screeplot وجد انكسار واضح بعد المكون

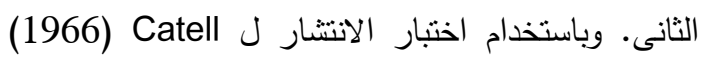
تأكد وجود المكونان بصورة يمكن استخدامها لأغراض

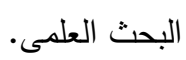

وبفحص قيم معاملات التشبع الواردة فى المصفوفة يتضح أن هناك سبعة بنود نثبعت على المكون الأول وهى : (لاننى غالبا مضغوطة بسبب مسؤولياتي الاسرية لاى صعوبة فى التركيز فى عملى، وبسبب الضغوط فى الصى

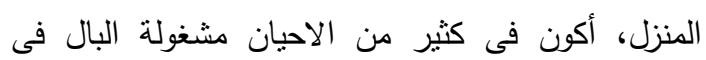

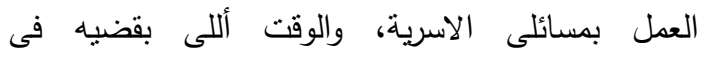

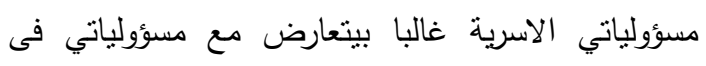

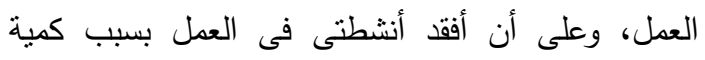

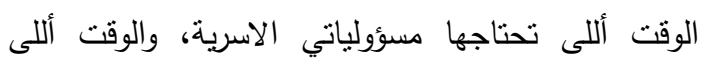

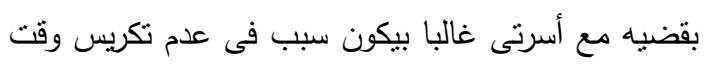
لانشطتى المفيدة فى مشوارى المهنى، والتوتر والقلق من فيكان

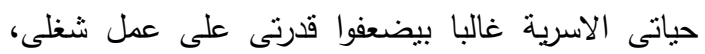


الاسرة تضيف مزيد من قوة التفسير المعنوى لصراع العمل

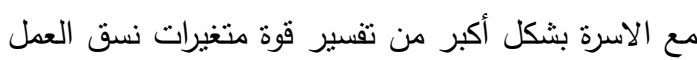
فقط، وذلك بعد ضبط متغيرات نسق العمل إحصائيا. وبالنظر الى متغيرات نموذج سمات الثخصية كما هو موضح في جدول رقم (3)، نجد أن قيمة معامل التحديد التزاكمى $\Delta R^{2}$

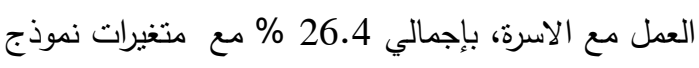

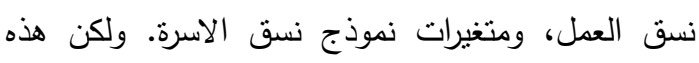

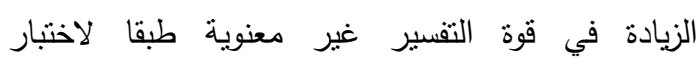
F change احصائا. احصائيا. وذلك بعد ضبط متغيرات نسق العمل ونسق الاسرة احصائيا. الامر الذى يمكن معه القول بان متغيرات

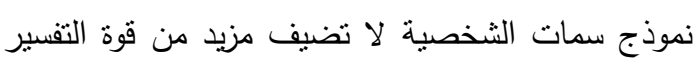

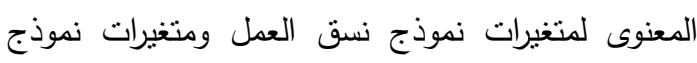

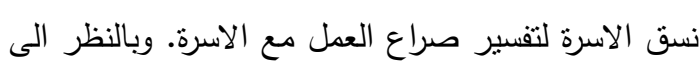

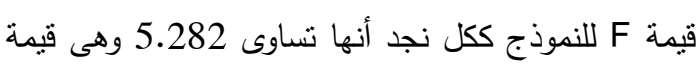

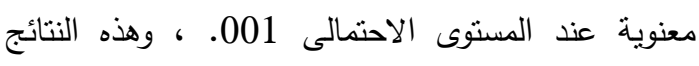

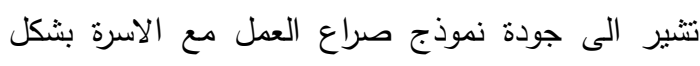
جزئى، وهذه الجودة الجزئية نرجع الى مساهمة كلا من الني

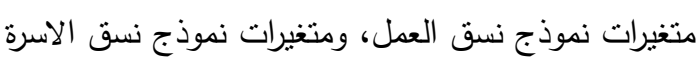
بشكل معنوى، ودون مساهمة متغيرات نموذج سمات

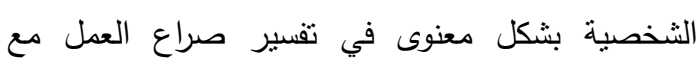
الاسرة. الامر الذى يسهم في تحقيق الهدف الثالث من هذا

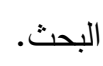
ولتحقيق الهدف الرابع من البحث وهو تقييم الاسهام

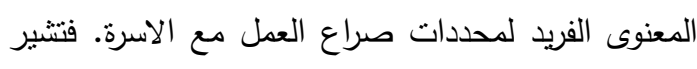

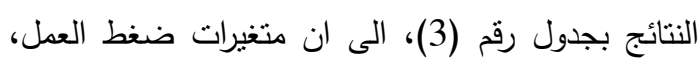

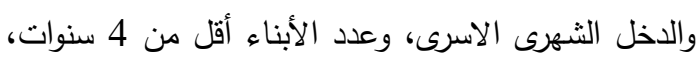

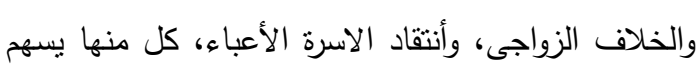

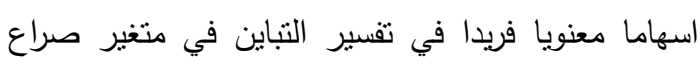

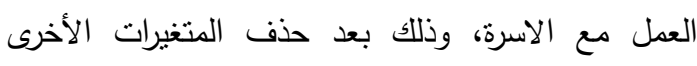

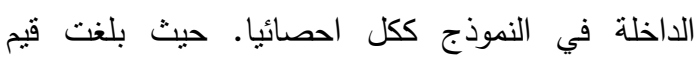

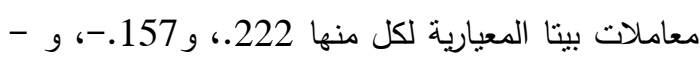

المقياس التسعة ككل فوجدت 780. ، وهى قيمة مرتفعة

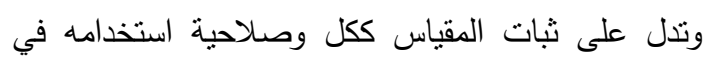
البحث العلمى، وبناء عليه فقد تقرر استخدام بنود المقياس

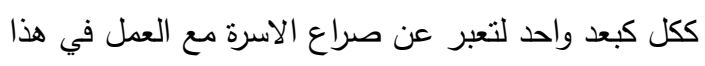

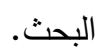

\section{3ierarchical نتائج الاتحدار المتعدد الهرمى}

\section{Multiple Regression Results}

ولتحقيق الهدف الثالث وحتى الهدف السادس من هذا البحث، سوف يتم استعراض نتائج الانحدار المتعدد

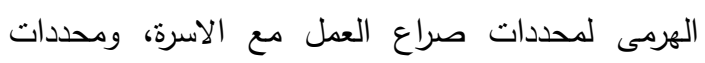

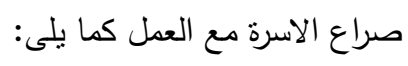

1.3 نتائج الانحدار المتعدد الهزمى لمحددات صراع

\section{العمل مع الاسرة}

يتضح من جدول رقم (3) نتائج الانحدار الخطى

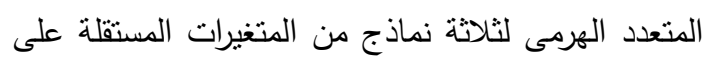

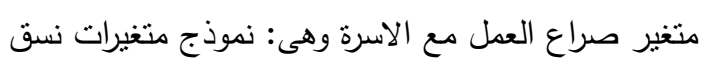
العمل، ونموذج متغيرات نسق الاسرة، ونموذج متغيرات

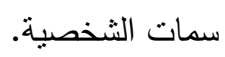
وبالنظر الى النتائج في جدول رقم (3) نجد أن قيمة معامل التحديد لنموذج متغيرات نسق العمل تفسر 10.7

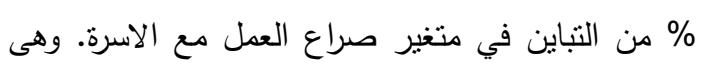

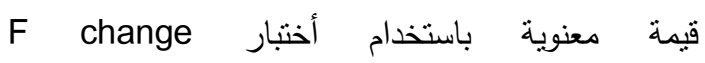

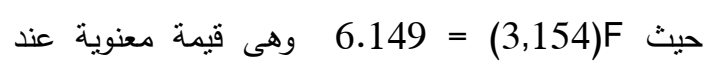
مستوى احتمالي 01.، وبإنخال متغيرات نسق الاسرة كما هو موضح في جدول رقم (3)، نجد أن قيمة معامل التحديد التزاكىى $\Delta R^{2}$ تفسر 12.7 \% من من التباين في

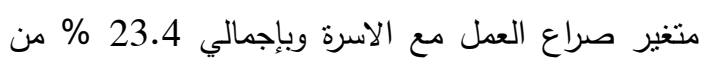
التباين مع نموذج متغيرات نسق العمل. هذه الزيادة في نسبة التباين معنوية باستخدام اختبار F change (اختبار

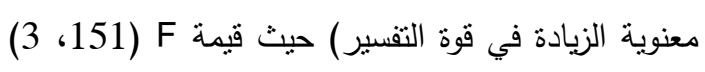

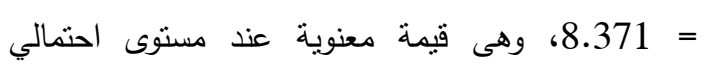

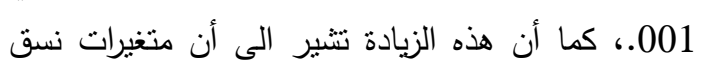


157، و 169.، و203.، على التزتيب، وجميع هذه متغير صراع العمل مع الاسرة نجد أن متغير ضغط العدل

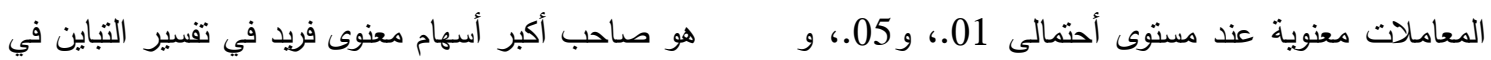
05.، و 05.، و 01.، على الترتيب. وبالنظر الى أكبر متغير صراع العمل مع الاسرة. يليه متغير انتقاد الاسرة المتغيرات ذات الأثر المعنوى الفريد في تفسير التباين في والاعباء.

جدول 3. نتائج الانحدار الغطى المتعدد الهزمى لمحددات نسق العمل ونسق الاسرة وسمات الثخصية على صراع العمل مع الاسرة وصراع الاسرة ميع العمل

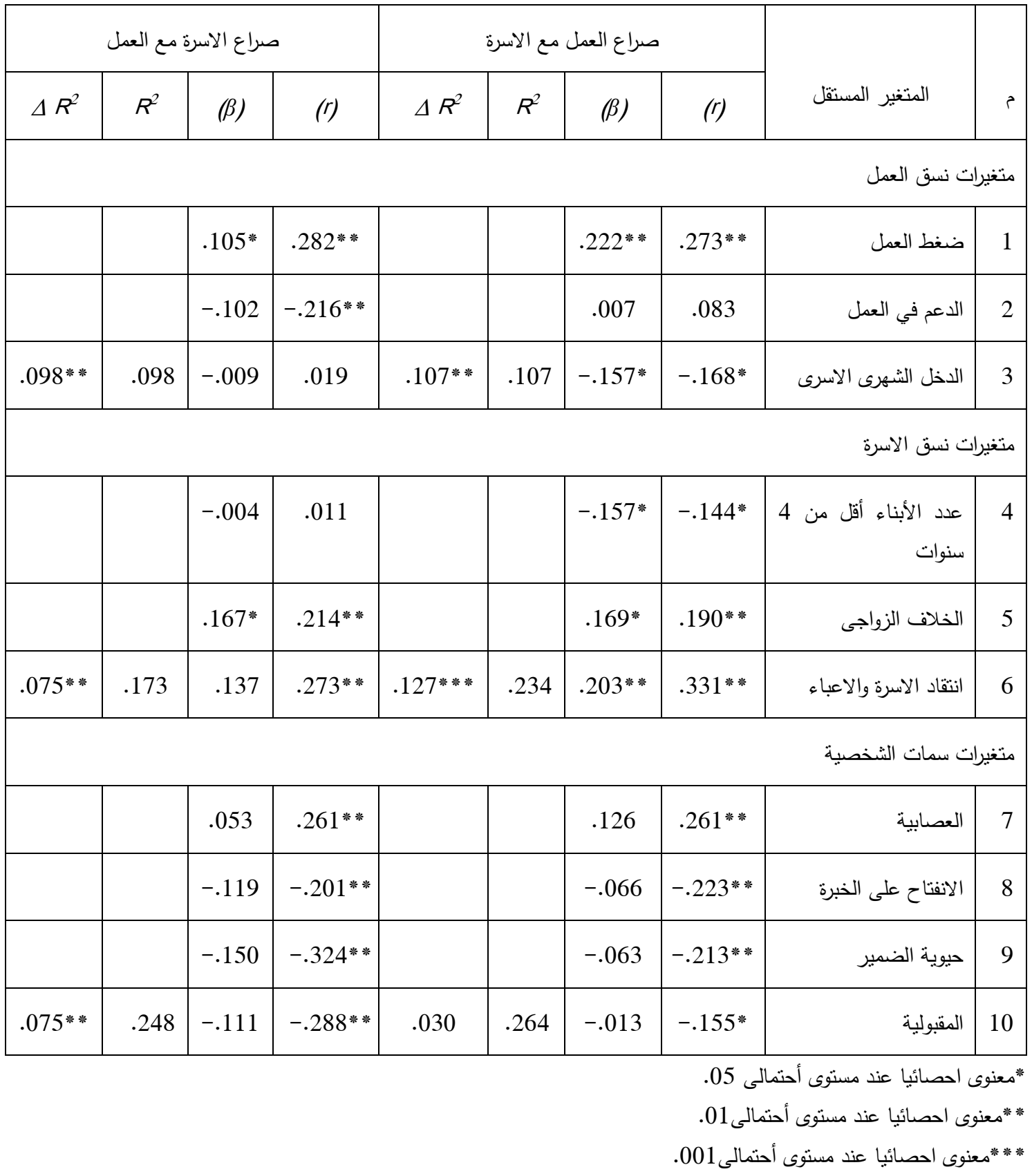


عند المسنوى الاحتمالى 01.، وذللك بعد ضبط متغيرات

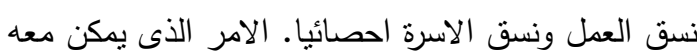
القول بان متغيرات نموذج سمات الثخصية تضيف مزيد الانيد من قوة التقسير المعنوى لمتغيرات نموذج نسق العمل

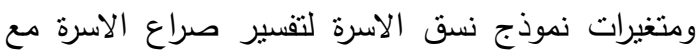
العمل. وبالنظر الى قيمة اختبار F للنموذج ككل نجد أنها نساوى 4.839، وهى قيمة معنوية عند المستوى الاحتمالى 00101، وهذه النتائج تثبير الى جودة نموذج صراع الاسرة

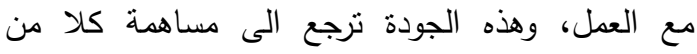
متغيرات نموذج نسق العمل، ومتغيرات نموذج نسق العقد الاسرة، ومتغيرات نموذج سمات الشخصية مجتمعه بشكل معنوى في تفسير صراع الاسرة مع العمل. الامر الذى لهن يسهم في تحقيق الهذف الخامس من هذا البحث. ولتحقيق الهدف السادس من البحث وهو تقييم الاسهام

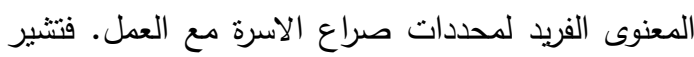
النتائج في جدول رقم (3)، الى ان متغيرى ضغط العمل، والخلاف الزواجى يسهمان اسهاما معنويا فريدا في تفسير

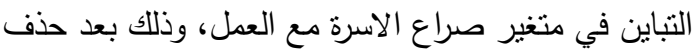
المتغيرات الأخرى الداخلة في النموذج ككل احصائيا. حيث بلغت قيم معاملات بيتا المعيارية لكل منهما 105.، و167.، على الترتيب، وقيم هذه المعاملات معنوية عند مستوى احتمالي 05.، وبالنظر الى أكبر المتغيرات ذات

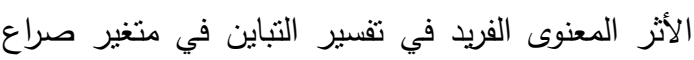

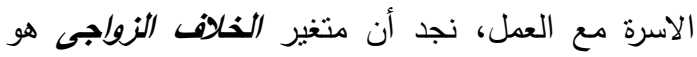
صاحب أكبر أسهام معنوى فريد في تقسير التباين في متغير صراع الاسرة مع العمل، ويليه متغير ضغط العمل.

\section{الاستنتاجات والمقترحات}

يهدف البحث الحالى الى تقييم البنية العاملية لمقياس صراع العمل والاسرة المقنن ذو الابعاد الستة والذى تم تعريبه من قبل الباحث في ظل ظروف البيئة الاجتماعية الريفية المصرية، وتحديدا لدى المرأة الريفية العاملة المتزوجة بمحافظة الغربية. كذللك التعرف على محددات صراع العمل والاسرة، والاثر المعنوى الفريد لهذه المحددات
2.3 نتائج الانحدار الخطى المتعدد اللهيمى

\section{لمحدات صراع الاسرة مع العمل}

يتضح من جدول رقم (3)، نتائج الانحدار الخطى

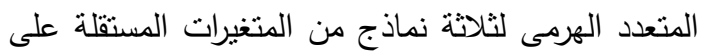
متغير صراع الاسرة مع العمل وهى نموذج متغيرات نسق العمل، ونموذج متغيرات نسق الاسرة، ونموذج متغيرات سمات الثخصية. وبالنظر الى النتائج بجدول رقم (3)، نجد أن قيمة معامل التحديد لنموذج متغيرات نسق العمل تفسر 9.8 \% من التباين في متغير صراع الاسرة مع العمل. وهى قيمة

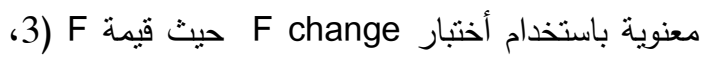
154

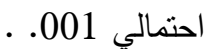

وبإنخال متغيرات نموذج نسق الاسرة كما هو موضح

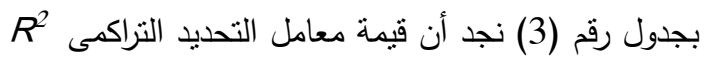

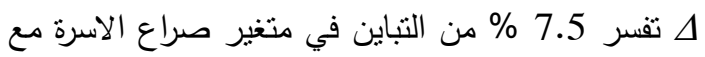

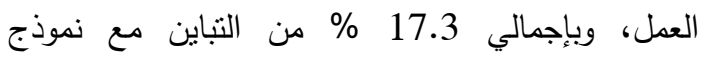
متغيرات نسق العطل. هذه الزيادة معنوية باستخدام أختبار F change (3) F احتمالى 01. ، كما أن هذه الزيادة تثبر الى أن متغيرات نسق الاسرة تضيف مزيد من قوة التفسير المعنوى لمتغير صراع الاسرة والعمل بشكل أكبر من تفسير قوة متغيرات نسق العمل فقط، وذلك بعد ضبط متغيرات نسق العمل إحصائيا. وبالنظر الى متغيرات نموذج سمات الثخصية كما هو موضح بجدول رقم (3)، نجد أن قيمة معامل التحديد التراكمى $4 R^{2}$ صراع الاسرة مع العمل، بإجمالي 24.8 \% من من التباين مع متغيرات نموذج نسق العمل، ومتغيرات نموذج نسق الاسرة. وهذه الزيادة في قوة التفسير معنوية طبقا لاختبار F change قيمة F (4، 147) = 3.644 وهى قيمة معنوية احصائيا 


\section{Ebad-Allah}

أسهاما معنويا فريدا مجتمعه بعد ضبط أثر كل من متغيرات نسق العمل ونسق الاسرة.

ومن ناحية أخرى فان اختيار المبحوثات باستخدام أسلوب يجمع بين طريقة المعاينة الاحتمالية الأسلوب العنقودى، وطريقة المعاينة غير الاحتمالية وذلك باستخدام أسلوب العينة العمدية، يجعل من الصعب نعميم نتائج هذا البحث، وعلى الرغم من ذلك فان نتائج البحث لا تتعارض

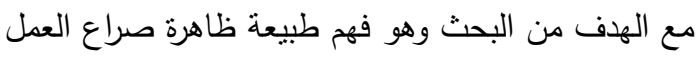
والاسرة لدى المرأة الريفية العاملة المتزوجة، وليس الهدف تعميم النتائج. وعلى الرغم من ذلك نقترح مزيدا من البحوث المستقبلية لنتمل فئات أخرى من المرأة سواء الريفية أو الحضرية، المنزوجة وغير المنزوجة، كذلك التعرف على دور النوع الاجتماعى في فهم ظاهرة صراع العمل والاسرة وذلك بإدخال النوع الاجتماعى كأحد المتغيرات البحثية والتي قد تساهم في فهم أفضل لظاهرة صراع العمل مع الاسرة. كذللك اختيار عينات من السيدات

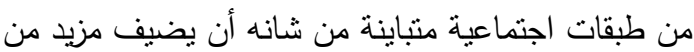
فهم الغموض في ظاهرة صراع العمل والاسرة. كذلك استخدام أساليب إحصائية أخرى لتأكيد البنية العاملية لمقياس صراع العمل مع الاسرة، ومقياس صراع الاسرة مع العمل كنمذجة المعادلات البنائية.

المراجع

عبد اللا، مختار محمد، فاطمة عبد السلام شربى، سماح محمد المداح، هدى محمد الليثى. (2014). اجتماعيات الاسرة: سفينة وملاحان في عالم مضطرب. القاهرة: دار فرحة للنشر والتوزيع.

Bartlett, M. (1954). A note on the multiplying factors for various chi square approximations. Journal of the Royal Statistical Society, (16): 296-298.

Bedeian, A. G., B. G. Burke and R. G. Moffett (1988). Outcomes of work-family conflict among married male and femal professional. Academy of management Journal, 14: 476-491.
لكلا الاتجاهين من الصراع، صراع العمل مع الاسرة، وصراع الاسرة مع العمل.

وأثنارت أهم نتائج البحث الى عدم تطابق البنية العاملية لأبعاد مقياس صراع العمل مع الاسرة، ومقياس صراع الاسرة مع العمل للمقياس الاصلى مع نتائج اختبار التحليل العاملى التوكيدى للبنية العاملية لكلا المقياسين عند مقارنتها بنتائج هذا البحث، سواء من حيث عدد الابعاد أو من حيث مضمون كل بعد. الامر الذى يحتاج الى مزيد من الأبحاث لتدعيم هذه النتائج.

كما أثنارت النتائج الى أن أكبر المحدات مساهمة معنوية فربدة في تفسير صراع العمل مع الاسرة هي متغير ضغط العمل ومتغير انتقاد الاسرة والاعباء. بمعنى اخر أن أكثر المتغيرات تقسيرا لصراع العمل مع الاسرة هو أحد متغيرات نسق العمل وهو ضغط العمل، بالإضافة الى أحد متغيرات نسق الاسرة وهو انتقاد الاسرة والاعباء. وهذه النتيجة تطابق مع نتائج الانحدار المتعدد الهرمى، حيث أشنارت النتائج الى اسهام متغيرات نسق الاسرة بالإضافة الى متغيرات نسق العمل اسهاما معنويا فريدا، وذلك بعد ضبط متغيرات نسق العمل احصائيا.

كذلك اشارت النتائج الى أن أكبر المحددات مساهمة معنوية فريدة في تفسير صراع الاسرة مع العمل هما متغيرى الخلاف الزواجى يليه متغير ضغط العمل. بمعنى أخر ان صراع الاسرة مع العمل يسهم في تفسيره أحد متغيرات نسق الاسرة وهو الخلاف الزواجى، بالإضافة الى متغير ضغط العمل كأحد متغيرات نسق العمل. وهو ما أكدته نتائج الانحدار الخطى المتعدد الهرمى، حيث اشارت النتائج الى اسهام منغيرات نسق الاسرة بالإضافة الى متغيرات نسق العمل اسهاما معنويا فريدا، وذلك بعد ضبط متغيرات نسق العمل احصائيا.

في حين لم تسهم أي من منغيرات سمات الشخصية اسهاما معنويا فريدا في تفسير أي من صراع العمل مع مع مي الاسرة أو صراع الاسرة مع العمل. بينما وجد أثز لإسهامها 
Frone, M. R. and M. Russell (1997). Relation of work-family conflict to health outcomes: a four-year longitudinal study of employed parents. Journal of Occupational and Organizational Psychology, 70: 325-335.

Goldberg, L. (1999). The development of five-factor domain scales from the IPIP item pool. (Retrieved 18/10/2016) http://ipip.ori.org/New IPIP-50-itemscale.htm

Greenhaus, J. H. and N. J. Beutell (1985). Sources of conflict between work and family roles. Academy of Management Review, 10: 76-88.

Grzywacz, J. G. and N. F. Marks (2000). Reconceptualizing the work-family interface: An ecological perspective on the correlates of positive and negative spillover between work and family. Journal of Occupational Health Psychology, 5: 111-126.

Hall, D. T. and J. Richter (1988). Balancing life and home life. What can organizations do to help? Academy of Management Executive, 11:213-223.

Henderson, A. K. (2014). Jesus didn't teach us to juggle: religious involvement, workfamily, and life satisfaction among african americans. Journal of Family Issues, 127.

Hertz, R. (1999). Working to place family at the center of life: Dual-earner and single parent strategies. Annals of the American Academy of Political and Social Science, 562: 16-31.

Hill, J. E. (2005). Work-family facilitation and conflict, working fathers and mothers, work-family stressors and support. Journal of Family Issues, 26: 793-819.

Hobfõll, S. H. (1989). Conservation of resources: A new attempt at conceptualizing stress. American Psychologist, 44 (3): 513-524.

Kaiser, H. F. (1970). A second generation little jiffy. Psychometrika, 35(4), 401-415.

Kaiser, H. F. (1974). An index of factorial simplicity. Psychometrika, 39(1): 31-36.
Bellavia, G. M. and M. R. Frone (2005). Work-family conflict. In J. Barling, E. K. Kelloway, \& M. R. Frone (Eds.), Handbook of work stress (pp. 113-147). Thousand Oaks, CA: SAGE.

Beutell, N. J. and U. Wittig-berman (1999). Predictors of work-family conflict and satisfaction with family, job, career, and life. Psychological Reports, 85: 893-903.

Blanch, A. and A. Aluja (2012). Social support (family and supervisor), workfamily conflict, and burnout: sex differences. Human Relations, 65 (7): 811-833.

Bruck, C. S. and T. D. Allen (2003). The relationship between big five personality traits, negative affectivity, type a behavior, and work-family conflict. Journal of Vocational Behavior, 63: 457472.

Carlson, D.S., K.M. Kacmar and L.J. William (2000). Construction and initial validation of a multidimensional measure of workfamily conflict. Journal of Vocational Behavior, 56: 249-276.

Cattell, R. B. (1966). The scree test for the number of factors. Multivariate Behavioral Research, 1(2): 245-276.

Clark, S. C. (2002). Employees-sense of community, sense of control, and workfamily conflict in native american organizations. Journal of Vocational Behavior, 61: 92-108.

Colman, A.M. (2003). Dictionary of Psychology, New York: Oxford.

Cohen, J. (1988). Statistical power analysis for the behavioral sciences. Hillsdale, New Jersey, Hove and London: Lawrence Erlbaum Associates.

Davis, J. A. (1971). Elementary survey analysis. Englewood Cliffs, N.J.: PrenticeHall.

Dilworth, J. E. L. (2004). Predictors of negative spillover from family to work. Journal of Family Issues, 25: 241-261.

Frone, M. R. (2000). Work-family conflict and employee psychiatric disorders: The national comorbidity survey. Journal of Applied Psychology. 85 (6): 888-895. 
Rothbard, N. P. (2001). Enriching or depleting? The dynamics of engagement in work and family roles. Administrative Science Quarterly, 46 (4): 655-684.

Schuster, T. L., R. C. Kessler and R. H. Aseltine (1990). Supportive interactions, negative interactions, and depressed mood. American Journal of Community Psychology, 18: 423-438.

Voydanoff, P. (2005a). Toward a conceptualization of perceived workfamily fit and balance: A demands and resources approach. Journal of Marriage and Family, 67: 822-836.

Voydanoff, P. (2005b). Work demands and work-to-family and family-to-work conflict: Direct and indirect relationships. Journal of Family Issues, 26: 707-726.

Voydanoff, P. and R. F. Kelly (1984). Determinants of work-related family problems among employed parents. Journal of Marriage and the Family, 46, 881-892.

Wayne, J. H., N. Musisca and W. Fleeson (2004). Considering the role of personality in the work-family experience: Relationships of the big five to work-family conflict and facilitation. Journal of Vocational Behavior, 64, 108130.

Whitehall Health Survey. (1989). Department of community medicine, University College of London, Civil Service Occupational Health Service (version S2).

Winslow, S. (2005). Work-family conflict, gender, and parenthood, 1977-1997. Journal of Family Issues, 26: 727-755.
Karatepe, O. M. and L. Bekteshi (2008). Antecedents and outcomes of workfamily facilitation and family-work facilitation among frontline hotel employess. International Journal of Hospitality Management, 27: 517-528.

Lewis, S. and C. L. Cooperc (1977). Stress in dual-career couples and stage in the life cycle. Journal of Occupational Psychology, 289-303.

Lewis, S. and C. L. Cooperc (1988). Stress in dual-earner families. In B. A. Gutek, A. H., Stromberg, \& L. Larwood (Eds.), Women and work: an annual review. Newbury Park, CA: Sage. Pp. 139-168.

Mennino, S. F., B. A. Rubin and A. Brayfield (2005). Home-to-job and job-to-home spillover: The impact of company policies and workplace culture. Sociological Quarterly, 46: 107-135.

National Survey of Midlife Development in the United States (MIDUS): 1995-1996. (2009). Documentation of scales and constructed variables in MIDUS 1 , Institute on Aging, University of Wisconsin, WI.

Netemeyer, R. G., J. S. Boles and R. McMurrian (1996). Development and validation of work-family conflict and family-work conflict scales. Journal of Applied Psychology, 81: 400-410.

Nomaguchi, Kei M. (2012). Marital Status, Gender, and Home-to-Job Conflict Among Employed Parents. Journal of Family Issues, 33(3): 271-294.

Parasuwmasn, S. and J. H. Greenhaus (1997). Integrating work and family. Westport, CT: Quorum Books. 


\title{
DETERMINANTS OF WORK-FAMILY CONFLICT AMONG MARRIED WORKING RURAL WOMAN IN GHARBIA GOVERNORATE
}

\author{
M. F. Ebad-Allah \\ Lecturer in Rural Sociology، Faculty of Agriculture - Tanta University. \\ mohammed.ebadallah@agr.tanta.edu.eg
}

\begin{abstract}
This paper was conducted to evaluate the construct of work-family conflict scale, as well as، to identify the determinants of work-family conflict. To achieve the research objectives, a clustering-purposive sample of 203 working married rural women was chosen at October of 2015. A personal interview technique was used to gather the data. Means, standard deviation, percentages, and hierarchical multiple liner regression were used to calculate the Results. Findings of multivariable analysis showed that the main two variables in the work-family conflict model with the biggest unique contribution were pressure at work, and family criticism and burden. While the main and the only two variables in the family-work conflict model with the biggest unique contribution were spouse disagreement and family criticism and burden. Paper limitations are identified and several promising directions for future research were discussed.
\end{abstract}

Key words: Gharbia Governorate, Hierarchical Multiple Liner Regression Technique, Married Working Rural Woman, Work-Family Conflict. 